\title{
5 Gallipoli in der Erinnerungskultur
}

Warum ist die Schlacht von Gallipoli, die bereits Zeitgenossen als Nebenkriegsschauplatz oder unnötige „Sideshow“ betrachteten, nach nun mehr als hundert Jahren immer noch von Bedeutung? Was wird warum von wem erinnert und wie äußern sich die unterschiedlichen Narrative in den jeweiligen nationalen Kontexten der teilnehmenden Kombattanten bzw. deren heutiger Nachfahren? Diesen Fragen muss eingehender nachgegangen werden, um die Tragweite und Bedeutung, die Gallipoli heute offensichtlich noch besitzt, verstehen zu können. Während unumstritten scheint, dass die zu schnellen britischen Planungen und die Unterschätzung des Gegners, Faktoren also, die oben bereits ausführlich geschildert wurden, für die Niederlage des Britischen Empire verantwortlich waren, wurden die Ereignisse auf der Halbinsel per se zur Basis ganz eigener Mythen, wie etwa die Legendenbildung in Australien sowie in der Türkei, die ebenfalls eingehender betrachtet werden müssen. Gerade in Australien hat die Begehung des ANZAC-Tages am 25. April jeden Jahres eine ganz besondere Bedeutung, wobei 2015, also zum hundertsten Jubiläum der Landung australisch-neuseeländischer Truppen auf der Halbinsel mehr als 10.000 Touristen aus diesen Ländern an den Feierlichkeiten in der Türkei teilnahmen. ${ }^{1}$ Darüber hinaus besitzen die Ereignisse der Jahre 1915/16 einen ganz anderen historiographischen Stellenwert als etwa in Deutschland und zahlreiche Untersuchungen halten das Interesse an Gallipoli als Forschungssujet aufrecht. ${ }^{2}$ Zudem wurde das Drama der ANZAC-Soldaten in der Kunst und im Theater, wie etwa dem Stück „Einst auf Chunuk Bair“ (Once on Chunuk Bair) von Maurice Shadbolt ${ }^{3}$, das in Neuseeland im April 1982 Premiere feierte und 1992 verfilmt wurde, verarbeitet.

Einen nicht zu unterschätzenden Anteil an der Entstehung solcher romantisierenden Deutungen des Krieges hat im Falle Gallipolis vor allem die Beschaffenheit des ehemaligen Kriegsschauplatzes selbst. Gerade die fälschlicherweise angesteuerte ANZAC-Landungszone war von einem schwierigen Terrain geprägt, in dem es keine Rückzugsmöglichkeiten für die Soldaten gegeben hatte, wodurch eine extreme Gedrängtheit, dadurch aber auch ein Übermaß an Kameraderie, sozusagen ein australisch-neuseeländisches „Wir-Gefühl“ angesichts der Enge des Raumes und der geteilten Gefahren - etwa beim Schwimmengehen von einem osmanischen Scharfschützen getötet zu werden - entstand. ${ }^{4}$ Ähnliche Entwick-

1 Macleod, Gallipoli, S. 3f.; Macleod, Reconsidering Gallipoli, S. 3 f.

2 Genannt sei hier beispielsweise Frances, Gallipoli.

3 Siehe dazu Wilson, Chunuk Bair.

4 Macleod, Gallipoli, S. 2f.

Ә OpenAccess. ( 2020 Frank Jacob, publiziert von De Gruyter. (cc) BY-NC-ND Dieses Werk ist lizenziert unter der Creative Commons Attribution-NonCommercial-NoDerivatives 4.0 License.

https://doi.org/10.1515/9783110694772-005 
lungen sind gleichfalls auf osmanischer Seite nachzuweisen, wobei hier besonders die Person Mustafa Kemals im Mittelpunkt der Legendenbildung steht. Militärisch betrachtet spielte die Erfahrung Gallipoli in der Zwischenkriegszeit in strategietheoretischen Diskussionen, aber auch konkreten Landungsoperationen wie etwa im Rifkrieg (1920 - 1926) bei Alhucemas in Marokko am 8. September $1925^{5}$ eine nicht zu unterschätzende Rolle.

Im Hinblick auf die Auswirkungen Gallipolis darf ferner eine Auseinandersetzung mit Winston Churchill und dessen Planungen und Abwägungen im Zweiten Weltkrieg nicht fehlen, denn schließlich dürften seine Entscheidungen, gerade wenn es um die alliierten Landungen in der Normandie geht, nicht unwesentlich von den Ereignissen der Jahre 1915/16 - und der anschließenden Erfahrung der öffentlichen Anprangerung für die britische Niederlage - geprägt gewesen sein. Warum Gallipoli im Gegensatz dazu in Deutschland und der Türkei heute wesentlich weniger im Fokus der öffentlichen Aufmerksamkeit steht, muss ebenfalls diskutiert werden.

\subsection{Frankreich}

Der amerikanische Historiker und Experte für die Geschichte des Ersten Weltkrieges, Jay Winter, bringt es auf den Punkt, wenn er feststellt, dass Gallipoli in der französischen Historiographie lediglich eine „Nebenattraktion“ (sideshow) ist. ${ }^{6}$ Französische Historiker, wie etwa Max Schiavon, sprechen hingegen vom „Desaster bei den Dardanellen “7 und stehen damit in einer Traditionslinie, die sich bis in die Zwischenkriegszeit zurückverfolgen lässt. ${ }^{8}$ Dabei wurde die Bedeutung der „Orientalischen Armee“ Frankreichs in der Öffentlichkeit lange vernachlässigt, da die Westfront des Ersten Weltkrieges klar im Fokus der Aufmerksamkeit rangierte und die Operationen bei den Dardanellen lediglich als koloniale Expedition wahrgenommen wurden, die zudem nur eine enttäuschende und ebenso blutige Erfahrung der französischen Soldaten während des Ersten Weltkrieges darstellte. ${ }^{9}$ Die Landungsoperation wird bis heute eher als eine „tragische Intervention“10 betrachtet, weshalb sie in der französischen Wahrnehmung nicht an prominenter

$5 \mathrm{Zu}$ dieser Landungsoperation und der Rolle Gallipolis siehe Alvarez (Gallipoli).

6 Winter, Divergences, S. 172.

7 Schiavon (Front).

8 Deygas, L’Armée, S. 9.

9 Schiavon, Front, S. 17.

10 Cochet, L’armée, S. 91. 
Stelle steht, wenn es darum geht, sich mit dem Ersten Weltkrieg auseinanderzusetzen. ${ }^{11}$

In englischsprachigen Darstellungen wird die Beteiligung französischer Truppen an den Landungen oft - bis auf eine kurze Erwähnung - ausgeklammert. Dabei darf die Bedeutung des Misslingens des Gallipoli-Planes für die französische Diplomatie nicht unterschätzt werden, denn der nicht erfolgte Durchbruch durch die Meerengen verhindert die Möglichkeit, das Zarenreich mit Waren zu versorgen und es für die militärische Allianz mit Frankreich zu stabilisieren. Aus Perspektive der europäischen Diplomatiegeschichte und den sich am Ende des Ersten Weltkrieges wandelnden politischen Gegebenheiten in Europa, müsste der Gallipoli-Kampagne, gerade im Hinblick auf ihre Langzeitwirkungen mehr Aufmerksamkeit geschenkt werden. In der französischen Historiographie werden die Ereignisse dagegen eher als vollkommenes und unvermeidbares Desaster geschildert. Im Gegensatz zur britischen Geschichtsschreibung, die sich immer wieder mit der Plausibilität der Kampagne und der Frage nach ihren Erfolgschancen befasst hat, standen derlei Überlegungen in Frankreich gar nicht zur Diskussion.

Schon die zeitgenössischen französischen Kommentatoren waren nur wenig davon überzeugt, dass eine Landungsoperation bei den Meerengen eine echte Alternative zur Konzentration der Truppen an der Westfront bieten konnte. Diese Meinung, setzte sich in den historischen Betrachtungen fort, sodass französische Historiker nur selten bereit waren, den Anteil Frankreichs an den Operationen zu betonen und Gallipoli zu ,einem Opfer wissenschaftlicher Vernachlässigung“12 werden musste. Vielmehr war das Bemühen der Untersuchungen darauf ausgelegt, die britische Schuld zu unterstreichen, um das Misslingen des Planes ganz auf die Schultern des ehemaligen Bündnispartners zu laden. Nach dem Ende des Großen Krieges wurde schließlich nur ein Denkmal gestiftet, das in Marseille der französischen Soldaten gedenkt, welche an den Operationen beteiligt waren. Aufgrund dieser geographischen sowie gedächtnispolitischen Randstellung verwundert es nicht, dass Gallipoli kaum Einzug in die Erinnerungskultur der Franzosen halten konnte.

Die französischen Veteranen der Gallipoli-Expedition wurden meist nicht beachtet und ihre Aufopferung für den Ruhm des Vaterlandes blieb ungewürdigt. Lediglich in zwei Vereinigungen, der Association nationale d'anciens combatants des Dardanelles und der Association des Poilus d'Orient wurde die Erinnerung an

11 Dutton, Supernumerary, S. 86. Die weitere Betrachtung folgt, sofern nicht explizit anders ausgewiesen, Dutton (Supernumerary).

12 Ebd. 
die französischen Soldaten der Operationen bei den Dardanellen wachgehalten. Das Gros der Franzosen interessierte sich mehr für den Krieg, der in ihrer unmittelbaren Nähe stattgefunden hatte. Allem, was nicht direkt Frankreich selbst betraf, kam lediglich eine Nebenrolle zu. Gerade Gallipoli, für das die Initiative von den Briten ausgegangen war, schien vernachlässigbar zu sein. General Joseph Joffre (1852-1931), der Befehlshaber der französischen Armee, war explizit gegen den Einsatz französischer Truppen außerhalb Frankreichs, da sie dort nicht dem Interesse des Heimatlandes dienten. Ähnliche Kritik wurde noch in den 1990er Jahren von französischen Historikern angeführt, wenn es um die Operationen bei den Dardanellen ging. ${ }^{13}$ Vielmehr wäre es im Sinne der französischen Führung gewesen, die Truppen gegen den deutschen Feind zu konzentrieren und nicht für sinnlose Manöver am östlichen Rand des Mittelmeeres zu verschwenden. Besonders im Hinblick auf die Bewertung der Offensiven Frankreichs bei Artois und in der Champagne wurde stets darauf verwiesen, dass dieselben hätten erfolgreich verlaufen können, wenn die Soldaten, die die politische Führung zur Unterstützung der Briten abgeordnet hatten, verfügbar gewesen wären. Die Zersplitterung der französischen Kräfte, die gerade in dem Moment erfolgte, als eine große deutsche Offensive an der Westfront zu erwarten war, wurde deshalb gerade aus militärischen Kreisen immer wieder kritisiert.

\subsection{Großbritannien}

Die Erinnerung an Gallipoli in Großbritannien ist in der Regel eine stille, in der der zahllosen Opfer der Kampagne gedacht wird, etwa wenn am Kenotaph im Londoner Stadtteil Westminster am Tag der Landung des britisch-australischen Expeditionskorps Kränze niedergelegt und an die Diversität des Britischen Empire sowie die heutige Einheit des Commonwealths, repräsentiert durch die verschiedenen Kontingente der Landungstruppen und die diese heute repräsentierenden Staaten, erinnert wird. ${ }^{14}$ Dort wurde Gallipoli zudem zu einem Emblem britischen Versagens und gerade weil es sich um ein militärisches Desaster handelte, setzten, schon während das Unternehmen noch in vollem Gange war, erste Diskussionen über die Verantwortung und die Durchführung der militärischen Operationen ein. Dabei spielten die Berichte der Dardanellen Kommission, die oben bereits geschildert wurden, eine nicht unbedeutende Rolle, da sie erst-

13 Siehe dazu Jauffret (Perspective) und ders. (Perspective, Part 2).

14 BBC (Gallipoli). 
mals für eine öffentlich breit rezipierte Untersuchung der Ereignisse sorgte. ${ }^{15}$ Des Weiteren entstanden nach dem Ersten Weltkrieg, wie in den anderen Nationalstaaten auch, offizielle Abhandlungen zu den Kriegsjahren, in denen Gallipoli selbstverständlich ebenfalls umfassend diskutiert wurde. ${ }^{16}$ In der DardanellenDiskussion spielten zudem die Schilderungen der journalistischen Begleiter des Unternehmens, wie etwa Ellis Ashmead-Bartlett eine große Rolle, da sie als verbriefte Kenner der Ereignisse galten. ${ }^{17}$ Hinzu kommen schließlich die Schilderungen der Teilnehmer selbst, die die Ereignisse unter den wachsamen Augen des öffentlichen Lesepublikums Revue passieren ließen und dazu beitrugen, einen britischen Gallipoli-Mythos zu schaffen, der sich scheinbar bis heute sehr hartnäckig gehalten hat.

Folgt man den Betrachtungen der britischen Historikern Jenny Macleod basiert dieser Mythos auf drei Säulen: „Die erste ist eine romantische Sicht von Kriegsführung im Allgemeinen und dieser Operation im Speziellen. Die zweite ist eine Hervorhebung des Heldentums der an der Operation Beteiligten, das für gewöhnlich deren Teilnehmer gegen die Kritik des Versagens verteidigt. Die dritte Säule ist eine spezifisch britische Betonung der Strategie der Operation. " ${ }^{18}$ Der Mythos per se ist dabei durchweg melancholisch, was, so Macleod, nicht verwundere, schließlich sei der Landungs- bzw. Invasionsversuch ja gescheitert. ${ }^{19}$ Dabei war es gerade die Tatsache, dass es sich bei Gallipoli um eine Niederlage handele, die zur Romantisierung der Gallipoli-Rezeption beigetragen hat. Im Gegensatz dazu erscheint eine Verteidigung der für die Dardanellen-Operationen gewählte Strategie unnötig und intellektuell betrachtet, eine Zeitverschwendung zu sein. ${ }^{20}$ Deshalb ist Macleod zuzustimmen, dass vor allem die beiden ersten Säulen des Mythos zu seiner Langlebigkeit beigetragen haben, denn ,sie formen eine emotionale Verteidigung, einen Zuckermantel für die bittere Pille der Niederlage. “21

Schon diejenigen, die selbst auf der Gallipoli-Halbinsel gekämpft hatten, waren ausgebildet genug, um mit den Klassikern der Literatur, etwa den Geschichten um Achilles, König Artus, oder Richard Löwenherz, in Berührung gekommen zu sein, sodass sie bereits mit einer bestimmten Auffassung von Rit-

15 Macleod, Reconsidering Gallipoli, S. 25-56.

16 Ebd., S. $57-102$.

17 Ebd., S. 103-146.

18 Ebd., S. 7.

19 Ebd.

20 Ebd., S. 10 u. S. 12.

21 Ebd., S.10. 
terlichkeit sowie einem romantisierten Kriegsbild in denselben zogen. ${ }^{22}$ Diese Präkonditionierung in Verbindung mit der geographischen Andersartigkeit des Kriegsraumes, die schon durch die Entfernung von den europäischen Fronten entstehen musste, sorgte dafür, dass Gallipoli schon von denen, die um die Einnahme der Halbinsel bzw. der Dardanellen fochten, als „der Krieg, wie er sein sollte“, nämlich „nobel, wagemutig, phantasievoll, ritterlich und tragisch“23 wahrgenommen wurde. Aufgrund dieser Wahrnehmungsebene war der Kampf um die Gallipoli-Halbinsel auch anti-modern und eben nicht hoch technisiert wie der Krieg, der Europa zerfleischte, sondern vielmehr eine Möglichkeit des Soldaten, Ruhm zu erwerben und durch seinen persönlichen Einsatz in schwierigem Terrain den Unterschied zwischen Sieg und Niederlage zu schaffen.

Das letztliche Scheitern war dabei nur schwer zu erklären und in den meisten Schilderungen, gerade denen der Verantwortlichen, wurde versucht, die Schuld möglichst anderswo abzuladen. Während Hamilton auf zu wenig Unterstützung durch die Politik und den Mangel an Munition und Männern verwies, kritisierten andere eben diesen Befehlshaber, der aufgrund mangelnder Führungsqualitäten für die schlussendliche Niederlage zur Verantwortung zu ziehen war. Der Gallipoli-Mythos beruht bis heute deshalb darauf, die Schuld an der Niederlage mit der Idee zu verknüpfen, der Erfolg der Operation sei durch den Verrat der Politik entstanden, weshalb man durchaus versucht ist, von einer britischen Version der Dolchstoßlegende zu sprechen, denn die Politiker hätten den Sieg der im Felde ungeschlagenen Soldaten verspielt. Zugleich basiert der Mythos auf der Idealisierung des Krieges, durch Betonung von Kameradschaft, Ehre und anderen identitätsstiftenden Momenten des Frontalltags, also auch des gemeinsamen Leidens. $^{24}$

Um dieses Konglomerat an Faktoren etwas eingehender zu analysieren, sollen im Folgenden einige der Schilderungen von Gallipoli-Veteranen und zeitgenössischen Kommentatoren, die noch während oder direkt im Anschluss an den Ersten Weltkrieg publiziert worden waren, ein wenig näher betrachtet werden. Der bereits oben zitierte englische Dichter und Poet John Masefield hatte selbst nicht an der Schlacht um Gallipoli teilgenommen, aber nach einer Lesereise in die Vereinigten Staaten, wo er mit Fragen zu den Ereignissen konfrontiert worden war, beim Foreign Office in London um Erlaubnis gebeten, eine Gegendarstellung zu kursierenden deutschen Berichten schreiben $\mathrm{zu}$ dürfen, die die britische Perspektive auf die Ereignisse aufzeige. Das Buch wurde zu einem Erfolg und schon

22 Ebd.

23 Ebd., S.13.

24 Vgl. ebd., S. 14. 
innerhalb eines Monats war die Erstauflage vergriffen. Dass Masefield sein Buch Ian Hamilton und den Männern unter seinem Kommando widmete, belegt, dass er keine „Verurteilungsschrift“ vorgelegt hatte. Vielmehr bediente die Darstellung den romantischen Mythos, der eben auf der Interpretation, welche die militärischen Operationen „nicht als Tragödie, nicht als Fehler, sondern als großen menschlichen Einsatz“ ${ }^{25}$ beschreibt. Zudem sei vieles Famose in der Militärgeschichte gerade das, was gescheitert war, schließlich gab es solcher Dinge und gescheiterter Nobelmänner viele in der Geschichte. ${ }^{26}$ Am Ende muss, so Masefield, ungewiss bleiben, ob nicht noch ein weiterer britischer Angriff zum Sieg über die von der Hitze ausgelaugten Osmanen ausgereicht hätte, das Blatt noch einmal zu wenden. ${ }^{27}$ Der Poet wählt als Ursache des Scheiterns am Ende schließlich die Variante, die den Gallipoli-Mythos so lange befeuerte: Es war die Entscheidung der Politiker in London, die einen Sieg vor Ort vereitelte. $\mathrm{Zu}$ früh hätte man aufgegeben, an die Kraft und das Durchhaltevermögen der eigenen Truppen zu glauben. Am Ende bliebe nichts als die Spuren, die die Soldaten auf der Halbinsel hinterlassen hatten und die sich in den zahlreichen Gräben und Verschlägen, die Deckung spendeten, widerspiegelten. Masefield geht davon aus, dass in ferner Zukunft nach den verbliebenen Überresten der Operation und der Gefallenen gegraben werden würde. Bedenkt man die touristische Entwicklung im Zusammenhang mit dem Gallipoli-Mythos, hatte er nicht gänzlich Unrecht. ${ }^{28}$ Die immer noch sichtbaren Schützengräben und Verhaue wären zwischen April 1915 und Januar 1916 das „zu Hause Tausender unserer Soldaten“ gewesen und „[d]ort lebten sie, haben gekocht und gewaschen, ihre Witze erzählt und ihre Lieder gesungen. Dort schwitzten sie unter ihren Lasten, und schliefen, und fielen nieder um zu sterben. [...] dort lagen sie in ihren dreckigen Lumpen und warteten auf den Tod; und dort liegen sie [...] zu Tausenden begraben, in kleinen einsamen Gräbern [...] oder in den Gruben der großen Schlachten. “29 Wenn nicht gerade eine dieser Schlachten tobte, dann waren es, so Masefield, „sonderbare, sonnenverbrannte, halbnackte Männer, die sich während ihrer Arbeiten mit den bronzenen Körpern von Göttern bewegten“"30 und wie die alten Ägypter eine Stadt errichteten und während der Staub ihre Uniformen mit der umliegenden Landschaft verschmolzen hätte, verlieh ihnen ihre Nacktheit eine Größe, die man kaum bei einem Bekleideten hätte ausmachen können. „Nur wenige von ihnen,“ so der

25 Masefield, Gallipoli, S. 3.

26 Ebd., S. 4.

27 Ebd., S.159.

28 Ebd., S.160f.

29 Ebd., S.161.

30 Ebd., S.165. 
Schriftsteller, „waren weniger als schön“ und in ihrer Gesamtheit bildeten gesamte Bataillone die Krönung der Schöpfung ab. ${ }^{31}$ Kritisch muss hier sicherlich bemerkt werden, dass das Bild, welches vom Poeten Masefield gezeichnet wird, ein geschöntes ist, das aber eben wesentlich zur Etablierung des Gallipoli-Mythos beigetragen haben dürfte.

John Graham Gillam, ein Veteran der Gallipoli-Landungen und der weiteren Kämpfe, publizierte 1918 sein überarbeitetes Tagebuch, in dem die oben angesprochenen romantischen Vorstellungen der aktiven Kombattanten selbst deutlich werden. Wie viele andere hatte Gillam geglaubt, dass der Große Krieg eine noble Angelegenheit wäre, in der sich Männer beweisen könnten, ebenso wie er annahm, dass die Soldaten die Gallipoli-Halbinsel heraufwanderten, während ihnen die Royal Navy den Weg freischoss. Konstantinopel wäre umgehend gefallen, die britischen Truppen hätten sich mit denen des Zaren vereint und die Mittelmächte durch eine Zangenbewegung in die Knie gezwungen. ${ }^{32}$ Ehrlicherweise gesteht er aus der Retrospektive aber auch, dass die Soldaten ihre Aufgabe mit zu wenig Ehrfurcht betrachteten..$^{33}$ „Gallipoli, die Dardanellen, Konstantinopel“; das klang einfach zu „romantisch und voller Abenteuer“. ${ }^{34}$ Nachdem die Evakuierung im Januar 1916 erfolgte, wandelte sich die Perspektive des Chronisten der Ereignisse, der gleichzeitig erklärte, wie das Kriegserlebnis die Veteranen verband:

den Horror der Halbinsel ließ ich für immer hinter mir. Von denen, die im März so leichtherzig von England aus in See gestochen waren, sind nur wenige übrig, aber diejenigen, die verbleiben, sind durch unsichtbare Fesseln aneinander gebunden. Diese merkwürdigen Monate - langweilig und aufregend, tragisch und humorvoll, verbracht unter den Augen des Feindes an einer fremden Küste - formen ein gemeinsames Band zwischen uns. ${ }^{35}$

Ebenso wie Masefield betont Gillam, dass die alliierten Truppen „geschlagen wurden - weniger vom Feind als vom Klima und den geographischen Gegebenheiten; aber geschlagen sind wir, und es bleibt nichts als die Niederlage wie Sportsmänner zu akzeptieren.“36

Eine ähnliche Haltung der Soldaten, also den Krieg als Sport zu begreifen, beschreibt William Ewing, der die Truppen als Kaplan während der GallipoliKampagne begleitete. In seinem Buch Von Gallipoli nach Bagdad (From Gallipoli

31 Ebd., S. 165f., Zitate von S. 165.

32 Gillam, Gallipoli, S. 5-6.

33 Ebd., S.6.

34 Ebd.

35 Ebd., S. 325.

36 Ebd. 
to Baghdad) beschreibt er den Zustand der Soldaten, als diese sich auf den Schiffen der feindlichen Küste näherten. Alle wurden ernster, aber alle schienen sich auf die bevorstehenden Aufgabe zu freuen, ${ }^{37}$ eine gewisse Schlachteneuphorie in der Hoffnung sicher geglaubter Siege kann den Teilnehmern der Dardanellen-Expedition nicht abgesprochen werden. Dabei war die bevorstehende Aufgabe alles andere als leicht. $\mathrm{Zu}$ Beginn des Krieges war sich nicht allein die osmanische Führung darüber bewusst, dass eine Landung auf der GallipoliHalbinsel schwierig war, zumal die Befestigungen der Meerengen eine ungestörte Durchfahrt schier unmöglich machten und deshalb zwangsläufig eine Landungsoperation erfolgen musste. Ungeachtet dieser schwierigen Ausgangslage weist Ewing allerdings darauf hin, dass der durchschnittliche Soldat ein Sportsmann sei, den eine ganz besondere Abenteuerlust auszeichne. ${ }^{38}$ Nachdem dieser an einen gerechten Grund für sein Tun glaube und von der Bevölkerung des eigenen Nationalstaats moralisch gestützt würde, war für den Autor sowie vermutlich ebenso viele seiner Leser klar, dass die britischen Soldaten den Erfolg verdienten, auch wenn dieser ihnen am Ende verwehrt bleiben würde. Darüber hinaus stellt Ewing fest, dass der „Soldat ein gefühlvoller Mann“ sei, der „die Tiefe und Zärtlichkeit seiner Liebe und Freundschaft“39 nicht verbergen könne. Schließlich sei der Soldat „tapfer und ritterlich“ wobei bemerkt wird, dass es sich nicht um „Tapferkeit, die keine Angst kennt, sondern um die, welche die Angst kennt und sie überwindet“40 handelt. Ewings Darstellung, ähnlich wie die von Gilam und Masefield vor ihm, trägt folglich dazu bei, die Kriegsromantik im Hinblick auf die Darstellung der britischen Soldaten zu betonen, indem deren Tugenden und Stärken hervorgehoben werden. Der Leser gewinnt stets den Eindruck, dass es eine unvergleichlich schöne Erfahrung gewesen sein muss, dieser Gruppe von Männern angehört zu haben, die ihr Ziel nur aufgrund widriger Umstände, die außerhalb ihres eigenen Kontrollvermögens lagen, nicht erreichen konnten.

Bryan Cooper veröffentlichte ebenfalls 1918 die Geschichte der 10. (Irischen) Division und ihrer Erlebnisse im Zuge der Kämpfe auf der Gallipoli-Halbinsel. Bezüglich der Frage, woran man denke, wenn man auf die Ereignisse zurückschaue, konstatiert der Autor:

Ein Menge von Erinnerungen häufen sich zusammen: trockene, sandgeflutete Schluchten, durstige Männer, die sich um eine Quelle scharen, Inder die ihre Mulis putzen, geschmei-

37 Ewing, Gallipoli, S. 7.

38 Ebd., S. 299.

39 Ebd., S. 300.

40 Ebd., S. 301. 
dige, halb-nackte Australier, ausgetrocknetes, sonnenverbranntes Gestrüpp, aber über alle Maßen erinnert man sich an die Gräber. Nicht ein Mann kehrte von der Halbinsel heim, ohne nicht einen Freund dort zurückgelassen zu haben, und es ist bitter daran zu denken, dass die letzte Ruhestätte derer, die wir geliebt haben, in den Händen unserer Feinde ist. ${ }^{41}$

Erwähnenswert schien Cooper zudem zu sein, dass der „Tod komische Bettgenossen" schuf, da die britischen Truppen kreuz und quer begraben worden und beispielsweise ein Waliser sein Grab neben dem eines Maori finden konnte. ${ }^{42}$ Männer unterschiedlicher Herkunft und Religion waren aus allen Ecken des Britischen Empire auf die Halbinsel gebracht worden, um zusammen für dieselbe Sache zu kämpfen und fanden zusammen ihr Grab. ${ }^{43}$ Dabei gab es für viele bedauerlicherweise noch nicht einmal ein Begräbnis, denn nur diejenigen, die im Lazarett starben, wurden mit den entsprechend notwendigen Riten und in Würde beerdigt. Cooper erklärt deshalb, dass das ,ganze Land ein einziger Schrein ist, geheiligt durch die Erinnerung und Hingabe an Pflicht und Selbstaufopferung, und kein Mann könne wünschen anderswo begraben zu sein als in der Erde, die er dem Feind abgerungen hat. “44 Die Darstellung bedient also wie die meisten anderen die Schaffung des Gallipoli-Mythos, im Zuge dessen die letzte Ruhestätte der Helden des Britischen Empire mystisch verklärt und sakral aufgeladen wird. Die Gemeinschaft der Truppe sei dabei so stark gewesen, dass selbst die Unterschiede zwischen Offizieren und einfachen Soldaten verwischt worden wären und diese durch ein „spirituelles Band“45 miteinander verbunden gewesen wären.

Dieses Soldatenbild floss in die britische Erinnerungskultur des Ersten Weltkrieges ein, nach dessen Ende gerade diesen Helden, die sich zum Wohle der Nation selbst geopfert hatten - und das nicht nur auf der Gallipoli-Halbinsel gedacht wurde. ${ }^{46}$ Dabei war der Gallipoli-Mythos zwar nur eines der identitätsbildenden Narrative der britischen Erinnerung an den Ersten Weltkrieg, ${ }^{47}$ aber sicherlich eines der langlebigsten.

41 Cooper, Division, S. 243.

42 Ebd., S. 244.

43 Ebd.

44 Ebd., S. 245.

45 Ebd., S. 246.

46 Die Erinnerungskultur im Vereinigten Königreich konnte dabei ganz unterschiedliche Formen annehmen bzw. in die jeweils regional vorherrschenden Kontexte eingebunden werden. Vgl. etwa Calder (War Memorial); D’Arcy (Remembering); Gaffney (Aftermath); Switzer (Unionists).

47 Vgl. dazu Macleod (Britishness). 
Die britischen Historiker deren Schaffensphase in der Zeit in den knapp zwei Jahrzehnten nach 1945 lag, ${ }^{48}$ betrachteten den Ersten Weltkrieg schließlich, und das oft in Abstraktion zum Zweiten Weltkrieg, als Großbritanniens „Großen Patriotischen Krieg“. ${ }^{49}$ Es wurde im Zuge dessen darauf hingewiesen, dass die Dimension des Weltkrieges eine wesentlich größere Auswirkung auf die britische Psyche hatte, als die des Krieges gegen Hitler und Nazideutschland. Zwischen totaler Selbstaufgabe im Angesicht der technisierten Materialschlachten, aber auch durchaus Ereignissen, wie eben denen um Gallipoli, die zur Selbst-Gratulation und -Glorifizierung gereichten, bot der Große Krieg somit ganz ambivalente Deutungsmuster für Historiker und Erinnerungswelten für die nachfolgenden Generationen an. ${ }^{50}$ Neben diesen unterschiedlichen Interpretationsansätzen wurden die Ereignisse im Zuge der historischen Aufarbeitung nach dem Ende des Zweiten Weltkrieges oft im Vergleich oder in Abstraktion zu den Ereignissen zwischen 1939 und 1945 gesetzt, wobei eine komparative Analyse zwischen den Landungen britischer Soldaten auf der Gallipoli-Halbinsel 1915 und den alliierten Landungen in der Normandie 1944 häufig auftauchen. Die beiden Ereignisse wurden zudem mitunter so in Relation zueinander gesetzt, dass die mediterrane Strategie des Empire und Churchills erst in den 1940er Jahren umgesetzt werden konnte, nachdem sie im Ersten Weltkrieg gescheitert war. ${ }^{51}$ Dessen ungeachtet gab es Stimmen, wie beispielsweise die von John Terraine (1921-2003), Correlli Barnett (*1927) und Cyril Falls (1888-1971), die den Tenor der militärischen Mehrheit der Kriegsjahre wiederholten und darauf verwiesen, dass der Krieg tatsächlich nur in Frankreich entschieden werden konnte und deshalb besonders Churchills Agieren für die Eröffnung einer zweiten Front bei den Dardanellen kritisierten. ${ }^{52}$ Barnett kritisierte in Großbritannien und seine Armee (Britain and Her Army, 1970) besonders den Einsatz vieler britischer Kontingente im Mittleren Osten, für deren Entsendung Churchill in beiden Fällen verantwortlich gewesen sei und damit zur Schwächung der britischen Truppen an den Punkten, an denen sie eigentlich gebraucht worden wären, also Europa, beigetragen habe. Selbst eine erfolgreiche Gallipoli-Kampagne wäre deshalb nur von zweifelhaftem strategischen Wert für das Britische Empire gewesen. ${ }^{53}$ Doch nicht nur historiogra-

48 Etwa Marder (Dreadnought; Guinn, Strategy; Home, Price; Roskill, Hankey; Woodward, Great Britain).

49 Campbell, War, S. 688.

50 Ebd., S. 690.

51 Ebd., S. 697.

52 Ebd.

53 Barnett, Britain, S. 425 f. 
phisch, sondern auch militärisch wurden die Ereignisse um Gallipoli seit dem Scheitern der Operation immer wieder diskutiert.

Die britische Royal Navy hatte im Ersten Weltkrieg drei entscheidende Erfahrungen gemacht: Die Schlachten von Jutland, Gallipoli und im Atlantik. All diese Ereignisse hatten einen nicht zu unterschätzenden Einfluss auf die Geschicke der Marine während des Krieges selbst, aber nicht alle von ihnen führten $\mathrm{zu}$ langfristigen Veränderungen. ${ }^{54}$ Nachdem die militärischen Operationen im Zuge der Gallipoli-Kampagne als Desaster rezipiert wurden, zerstörte die Erfahrung die britische Sicht auf eine durchaus wichtige Form der Kriegsführung, nämlich der umfangreichen Landungsoperationen im Zusammenspiel von Heer und Marine für die kommenden 25 Jahre, wobei der amerikanische Marinehistoriker Arthur J. Marder (1910-1980) in seiner Aussage, dass die amphibische Kriegsführung völlig diskreditiert worden sei, zu weit ging. ${ }^{55}$ Nicht diskreditiert, aber doch zumindest verzerrt, so der Militärhistoriker David MacGregor. ${ }^{56} \mathrm{Er}$ konstatiert weiter, dass die britischen Planer zu sehr über amphibische Operationen nachdachten und sich im Zuge dessen dem seit der „Schlappe von Gallipoli“ grassierenden Pessimismus ergaben. In ihrer Furcht, die Fehler von $1915 \mathrm{zu}$ wiederholen, scheiterten sie daran, dieselben zu überwinden.

Dabei war es nicht so, dass man dem Problem der Gallipoli-Operationen in den militärischen Kreisen Großbritanniens nach dem Ende des Ersten Weltkrieges keine Beachtung geschenkt hätte. Die Admiralität hatte schon 1919 der Aufstellung des Mitchell Committee zugestimmt, das die Ereignisse um Gallipoli untersuchen und einen umfassenden Bericht darüber zu verfassen hatte. Ebenfalls bereits 1919 veranstaltete das Army Staff College (Camberley) eine Übung, an der Veteranen der Dardanellen-Operationen beteiligt waren und der Kommandant der Bildungseinrichtung, Warren Hastings Anderson (1872-1930) sprach sich in seinem Bericht dafür aus, ein von allen Waffengattungen beschicktes Komitee zu etablieren, dass die Doktrinen der amphibischen Kriegsführung diskutieren und gegebenenfalls revidieren sollte. ${ }^{57}$ Die Mitglieder des Gremiums empfahlen, eine tiefgehendere Analyse der kombinierten amphibischen Kriegsführung durchzuführen und erstellten auf Basis derselben 1925 ein Handbuch für gemeinschaftliche Operationen des Heeres und der Marine (Combined Operations Manual), von dem überarbeitete Neuauflagen in den 1930er Jahren - 1931 und 1938 - erschienen. Zudem wurde in Vorlesungen am Royal Navy's War College in Greenwich in der Zwischenkriegszeit die Geschichte der kombinierten Marine-Heer-Operatio-

54 MacGregor, Use, S. 603.

55 Marder, Dardanelles, S. 52.

56 MacGregor, Use, S. 606.

57 Ebd. 
nen bei Gallipoli analysiert und diskutiert. Das Navy Staff College führte darüber hinaus immer wieder theoretische und praktische Übungen durch, bei denen es in den 1920er und 1930er Jahren darum ging, die mögliche Zusammenarbeit zwischen Armee, Marine und der Marineinfanterie zu eruieren und exerzieren. Um den Erfolg solcher Operationen in der Zukunft besser gewährleisten zu können, richteten die Stabschefs 1938 ein Inter-Service Training and Development Centre (ISTDC) ein, an denen Angehörige der entsprechenden Waffengattungen sich mit solchen Vorhaben in ihrer ganzen Tragweite vertraut machen konnten. ${ }^{58}$ Aufgrund der umfangreichen Studien gingen die britischen Planer davon aus, dass zukünftige amphibische Operationen kleiner und einfacher angelegt sein und zwingend auf strikter Geheimhaltung, um den Überraschungseffekt nicht zu gefährden, bestehen müssten. Deshalb hätten Landungen in einem möglichen Krieg der Zukunft auch in der Nacht stattfinden sollen. Etliche der Studierenden kamen allerdings zu dem Schluss, dass amphibische Angriffe überhaupt nicht praktikabel seien. Die Entwicklung neuer Waffentechniken - vor allem Maschinengewehr, Artillerie und Flugzeuge -, die eine einfachere Verteidigung ermöglichten und gleichzeitig eine Anlandung von Truppen zusätzlich erschwerten, schlossen in der Theorie einen Erfolg solcher Operationen aus. Die von Gallipoli geprägte, oft durchaus als feindlich zu bezeichnende Ablehnungshaltung vieler Offiziere, erschwerte deshalb eine offenere Betrachtung der Möglichkeiten, die gemeinschaftliche Planungen für operative Umsetzungen zu liefern in der Lage waren.

Da eine totale Geheimhaltung nur schwer umzusetzen war, selbst wenn nicht so schlampig wie im Vorfeld der Gallipoli-Operationen verfahren würde, zweifelten die meisten Planer des britischen Militärs schlicht und ergreifend an der Praktikabilität einer Landungsoperation gegen einen verteidigten Strandabschnitt. ${ }^{59}$ Der „überzeugende Pessimismus“60 beherrschte die britischen Gemüter und eine übervorsichtige Haltung besetzte die Schaltstellen der militärischen Planung. Nur absolute Geheimhaltung, der Überraschungsmoment auf Seiten der Angreifer, während einer Operation im Schutze der Nacht schien sinnvoll und erfolgversprechend. Jedwede andere Umsetzungsinitiative wurde konsequenterweise a priori abgelehnt. Nicht überraschend ist es deshalb, dass die späteren britischen Vorbereitungen zur Landung in der Normandie auf wenig Vorarbeiten bzw. echte Erfahrungswerte zurückgreifen konnten. Es gab weder ausreichend Landungsfahrzeuge noch existierten theoretische Vorgaben für den Feuerschutz solcher Operationen von See aus. Folgerichtig musste 1942/43 improvisiert wer-

58 Ebd., S. 605-607.

59 Ebd., S. 607.

60 Ebd., S. 608. 
den, um diese Wissens- und Erfahrungslücken zu schließen, um sich auf die entscheidende Landung im Juni 1944 vorbereiten zu können. ${ }^{61}$

Bei jeder wie auch immer gearteten Landungsoperation wären die Marineinfanteristen des Empire, die Royal Marines, von entscheidender Bedeutung gewesen, allerdings stellten diese im ersten Drittel des zwanzigsten Jahrhunderts kaum ein ernstzunehmendes Angriffspotential dar. ${ }^{62}$ Die Einheiten waren eher in ad hoc durchzuführenden Operationen im kolonialen Raum von Nutzen, wo sie improvisierte Strafaktionen und Überfälle ausführten, allerdings fehlte es den Einheiten an einer dauerhaften Organisationsstruktur, an notwendiger Ausrüstung sowie einer dezidiert erarbeiteten Doktrin, die es den Marineinfanteristen ermöglicht hätte, einen verteidigten Strandabschnitt anzugreifen und eventuell einzunehmen. ${ }^{63}$ Zur Eruierung der eigenen Möglichkeiten richtete die Admiralität 1923 das von Admiral Charles Madden (1862-1935) initiierte und nach ihm benannte Madden Komitee ein, welches die genauen Einsatzbereiche der Marineinfanterie festzulegen hatte. Die Aufgaben der Einheit wurden in einem Bericht des Jahres 1924 schließlich wie folgt bestimmt: In Kriegszeiten sollte sie

1. dazu genutzt werden, die Besatzungsstärke der größeren Schiffe zu erweitern und die Schiffsartillerie besetzen,

2. unabhängige Kontingente bereitstellen, um der Flotte bei der Mobilisierung unterstützend beizustehen sowie Operationen zur Einnahme oder zur Verteidigung temporärer Marinebasen durchzuführen, und

3. als verbindendes Element zwischen Armee und Marine $\mathrm{zu}$ agieren. ${ }^{64}$

Die tatsächliche Umsetzung dieser Aufgaben verlief dabei eher schleppend und in den kommenden Jahren wurde kaum etwas getan, um eine wirklich unabhängige Einsatztruppe $\mathrm{zu}$ formen, was unter anderem mit Budgetbeschränkungen für derlei Unterfangen einherging. Während einige Einheiten in den 1920er Jahren beispielsweise nach Konstantinopel und Shanghai entsandt worden waren, um militärische Aufgaben zu übernehmen, wurden dieselben allerdings immer ad hoc zusammengestellt, bis zur Erledigung ihrer Pflichten entsandt, danach jedoch umgehend nach Hause geschickt und wieder aufgelöst. $\mathrm{Zu}$ einer echten und auf Dauerhaftigkeit beruhenden Struktur kam es deshalb nicht, was den Einsatz der Marineinfanterie als kontinuierlich existenter Spezialeinheit unmöglich machte. Das Komitee der Stabschefs sanktionierte dieses Manko, wenn 1938 erklärt wurde,

61 Ebd.

62 Bittner, Sword, S. 347.

63 Ebd.

64 Ebd., S. 349. 
dass im nächsten Krieg nicht mit amphibischen Kampfeinsätzen zu rechnen sei, eine Meinung, die von der Armeeführung geteilt wurde. Selbst die Royal Airforce gab zu bedenken, dass man keine solche Einheit benötigen würde, da eine Landungsoperation so unwahrscheinlich schien, dass ein auf einer eben solchen basierendes Argument kaum die Kosten einer Spezialeinheit rechtfertigte. ${ }^{65}$

Ungeachtet dieser generellen Ablehnung von Landungsoperationen amphibischen Charakters war es immer wieder Churchill, der für die Verzögerung bei der Etablierung einer zweiten Front im Westen während des Zweiten Weltkrieges kritisiert worden war, nicht selten mit dem Hinweis darauf, dass er eine Landungsoperation aufgrund der Erfahrung Gallipolis auf jeden Fall vermeiden wolle. Offensichtlich scheint das aber, bedenkt man die Absagen an solche Operationen, die aus den entscheidenden Gremien der militärischen Planer im Großbritannien der Zwischenkriegszeit geäußert wurden, unmöglich ein solider Erklärungsansatz zu sein. Es gilt daher, sich die Rolle Churchills im Zweiten Weltkrieg, im Hinblick auf einen möglichen Einfluss des Gallipoli-Erlebnisses etwas näher zu beleuchten.

Als Churchill 1930 sein frühes Leben in einem autobiographischen Werk Revue passieren ließ, stellte er fest, dass sich „der Zustand der Gesellschaft, die Grundlagen der Politik, die Methoden des Krieges, die Aussicht der Jugend, der Maßstab der Werte, alle verändert hatten“ und zwar in einem Ausmaß, das der spätere britische Premierminister ,nicht ohne eine gewalttätige Revolution in solch kurzer Zeit für möglich gehalten“ hätte. ${ }^{66}$ Geboren als „Kind der viktorianischen Ära“67, in der die Macht des Britischen Empire unerschütterlich schien, musste er schließlich im Ersten Weltkrieg erleben, wie Freunde, beispielsweise in der „schrecklichen Schlacht von Suvla Bay“68, ihr Leben verloren. Und doch war Churchill nicht ungeneigt, seiner Meinung über den Krieg und das Hochgefühl, das derselbe in ihm hervorrief zu berichten. Während er am Royal Military College in Sandhurst studierte, frustrierte es ihn, dass die Studien nur in der Theorie von Nutzen sein sollten, denn er empfand es als großes Unglück, „dass das Zeitalter der Kriege zwischen zivilisierten Nationen für immer zu einem Ende gekommen sein sollte. “69 Fast traurig bemerkt er: „Wenn ich nur einhundert Jahre eher gelebt hätte. Was für glorreiche Zeiten sollten wir haben! Stell Dir vor 179319 Jahre alt zu sein mit mehr als 20 Jahren Krieg gegen Napoleon vor uns!“70 Pazifist war Chur-

65 Ebd., S. 350 f.

66 Churchill, Commission, vii.

67 Ebd.

68 Ebd., S. 41.

69 Ebd., S. 44.

70 Ebd. 
chill sicherlich nicht, denn er bedauerte zutiefst, dass die Britische Armee seit dem Krimkrieg keinen Schuss mehr auf „weiße Truppen“ abgefeuert hatte, und „nun, da die Welt zunehmend sensibel und pazifistisch wird - und auch so demokratisch - waren die großen Tage vorbei. " ${ }^{11}$ Dessen ungeachtet, zur Freude des seine Jugend reflektierenden Churchills, konnte festgestellt werden: „Aber glücklicherweise gibt es noch Wilde und barbarische Völker." ${ }^{\text {72 }}$ Selbst die Niederlage von Gallipoli mit den schweren Verlusten, ebenso wie die Gefallenenlisten des Großen Krieges, haben Churchills positives Bild des Krieges, das er knapp 15 Jahre nach dem Desaster der Dardanellen-Operationen einer breiten Öffentlichkeit präsentierte, offenbar nicht zum Wanken gebracht. ${ }^{73}$

Inwieweit Gallipoli Churchills Selbstwahrnehmung sowie seine „Sicht der Dinge" beeinflusste, kann anhand seiner eigenen frühen Reflexionen autobiographischen Charakters nicht bestimmt werden. Fakt ist, dass der große britische Staatsmann nicht nur einer der einflussreichsten politischen Figuren des 20. Jahrhunderts gewesen ist, sondern eine sehr komplexe Persönlichkeit besaß, die neben der politischen Brillanz und Intelligenz auch von Witz, einem gewissen Draufgängertum sowie einer stark ausgeprägten Egozentrik gekennzeichnet war. ${ }^{74}$ Sich mit ihm zu beschäftigen, so die New Yorker Journalistin Brooke Allen, heißt einem Mann zu begegnen, „der anmaßend ehrgeizig, wichtigtuerisch, schludrig, rücksichtslos, und ein Monster des Egoismus war, und doch als der größte britische Staatsmann des 20. Jahrhunderts, möglicherweise sogar der gesamten Geschichte dieser Nation" ${ }^{\text {"75 }}$ betrachtet wird. Oft des „latenten Bonapartismus" verdächtigt, hoffte er, wie es Allen weiter formuliert, in seiner späteren Karriere der „englische Mussolini““76 zu werden. Dabei halfen ihm seine Überredungskünste, seine moralische Autorität sowie seine Persönlichkeit, die ihn, nicht nur im Zuge der Planungen zur Gallipoli-Kampagne, in die Lage versetzte, andere von seiner eigenen Meinung zu überzeugen und in seinen Bann zu ziehen. Wie andere junge und aufstrebende Männer, „war Churchill hungrig nach einem Amt und visierte den größten Preis von allen, den Posten des Premierministers, an. “77 Oft sprach er diesen Wunsch lauthals aus und machte keinen Hehl aus seinen eigenen Ambi-

71 Ebd.

72 Ebd.

73 Es böte sich an Churchills Wahrnehmung von Krieg im Allgemeinen sowie des Ersten und Zweiten Weltkrieges im Speziellen einmal ausführlich zu analysieren, dieses Vorhaben muss hier jedoch aufgrund der eigentlichen Intention des vorliegenden Buches zurückgestellt werden.

74 Arnett, Churchill, S. 609.

75 Allen, Sum, S. 312.

76 Ebd.

77 Addison, Careers, S. 185. 
tionen, was nicht immer zu seinem Vorteil aufgenommen wurde. Er selbst glaubte daran, „ein Mann des Schicksals“ zu sein und sah sich „,irgendwo in der Zukunft große Taten auf der Bühne der Geschichte vollbringen." ${ }^{78}$

Wie oben bereits erwähnt, glaubte Churchill dabei fest an die Rolle des Britischen Empire in der Welt und dessen Vorbestimmung, die Geschicke der Welt zu bestimmen. Neben diesen entscheidenden Faktoren seines politischen Handelns hat der amerikanische Psychologe Jeffrey Arnett Churchills Sensationslust als eine der treibenden Kräfte hinter den Aktionen des britischen Politikers und Premierministers identifiziert. Zeit seines Lebens hätte dieser „einen außergewöhnlich großen Appetit auf Sensation und Erlebnis sowie eine Liebe für das rücksichtslose Abenteuer gezeigt. “79 Gesagt haben soll der spätere Premierminister unter anderem: „Ich mag es, wenn Dinge passieren und wenn sie nicht passieren, dann sorge ich dafür, dass sie es tun. ${ }^{\text {"80 }}$ Churchill soll folglich stets auf der Suche nach dem Extrem gewesen sein und in den Perioden seines Lebens, in denen er sich nicht mehr selbst in waghalsige Erlebnisse stürzen konnte, den „Kick“ durch seine oft forschen und teils nur wenig durchdachten, aber dafür schnellen und folgenreichen politischen Aktionen erhalten haben. So handelte er schließlich ganz im Sinne seiner Ambitionen, wenn er sich in seinen jungen Jahren in kriegerische Auseinandersetzungen stürzte, da ein Bekanntheitsgrad als Kriegsheld den Einzug in politische Ämter versprach, wodurch Churchill Vergnügen, also die Aufregungen des Krieges per se, mit der Erfüllung seiner persönlichen Ziele und Wünsche verquicken konnte. ${ }^{81}$

Eine negative Nebenwirkung der Sensationslust war jedoch Churchills Intoleranz von Monotonie und Stillstand.$^{82}$ Das, in Verbindung mit dem Enthusiasmus für Krieg auf historischer Bühne, auf der über Größe oder Niedergang entschieden wurde, sorgte unter anderem dafür, dass Churchill den Beginn des Großen Krieges durchaus fröhlich zu begrüßen schien. ${ }^{83}$ Von diesem Moment an agierte der spätere Premierminister für die Durchführung von Marineoperationen, für die er nach dem Scheitern der Gallipoli-Operationen seinen Hut als Erster Lord der Admiralität nehmen musste. Kurz nach seinem politischen Scheitern wandte sich der so ambitionierte Churchill wieder dem Krieg zu und meldete sich freiwillig zum Dienst im Weltkrieg und diente zwischen November 1915 und Mai 1916 als Offizier an der Westfront. Churchill hatte nicht zu Unrecht das Gefühl, als Sün-

78 Ebd.

79 Churchill, Commission, S. 605.

80 Zitiert nach Manchester, Lion, S. 812.

81 Churchill, Commission, S. 74.

82 Arnett, Churchill, S. 613.

83 Manchester, Lion, S. 10. 
denbock für die gescheiterte Dardanellen-Offensive an den Pranger gestellt zu werden, während andere ihren eigenen Kopf aus der Schlinge zogen. Bereits im Juli 1917 wurde er von Premierminister David Lloyd George wieder als Munitionsminister eingesetzt und setzte seine politische Karriere fort. Es waren nur wenige Politiker, die am Genie Churchills zweifelten, selbst wenn sie seinen Stil und seine ungestüme Art nicht immer guthießen. Der britische Historiker Paul Addison weist darauf hin, dass „Churchill innerhalb der politischen Elite als gescheitertes Genie galt [...] Das fehlende Teil in dem sonst so wundervollen Mechanismus von Churchills Hirn war das Urteilsvermögen: Deswegen existierte immer die Gefahr, dass er seine Mitstreiter ins Desaster stürzen würde. “84

Für gut zwei Jahrzehnte nach dem Ende des Zweiten Weltkrieges wurde Churchills Status als der „bedeutendste lebende Engländer“ allerdings selten in Frage gestellt. Historiker hatten scheinbar zunächst wenig über ihn zu sagen, zumal sich Churchill in seiner sechsbändigen Abhandlung zum Zweiten Weltkrieg selbst sehr umfassend zu Wort gemeldet hatte. Diese Darstellung wurde als die Wahrheit akzeptiert, denn Churchill selbst sprach sich darin über die wichtigen Ereignisse der vergangenen Jahre aus. Erst mit seinem Tod 1965 wurde sein Andenken aus den Händen von Zeitgenossen gelöst und ging in die Obhut der Historiker über, die sich wesentlich kritischer mit der Person und der Bedeutung des britischen Staatsmannes auseinandersetzten. Der Krieg per se hatte Churchills Leben nicht nur aufgrund der oben angesprochenen Sensationslust bestimmt, sondern auch seine politische Karriere wurde zweimal, nämlich 1915 und 1940, entscheidend vom Krieg beeinflusst. Während Gallipoli seinen Fall bedingte, machte der Zweite Weltkrieg Churchill letztlich doch zum Premierminister. Der Politiker, der zuvor oft als unberechenbar und sogar gefährlich galt, wurde durch die Ereignisse seit 1939 zur Lichtgestalt, die gleichsam als eine der größten Staatsmänner und Strategen des 20. Jahrhunderts gehuldigt wurde. ${ }^{85}$ Aus heutiger Sicht gibt es etliche Kontroversen, die sich um die Person Churchills ranken, wobei die Dardanellen-Kampagne eine durchaus prominente Position einnimmt.

Besonders in Bezug auf den Zweiten Weltkrieg wurde über die Bedeutung dieser Erfahrung für die Entscheidungen des britischen Premierministers spekuliert, denn seine „strategische Reputation bewegte sich zwischen Heldenverehrung und Sündenbock hin und her“. ${ }^{86}$ Eine der extremen Positionen in diesem Streit ging so weit, zu behaupten, dass Churchills Strategievorstellungen beinahe zur Niederlage der Alliierten geführt habe, weil er von Alpträumen und Ängsten,

84 Addison, Careers, S. 191.

85 Ebd., S. 183-185.

86 Baxter, Churchill, S. 7. 
die auf seinen eigenen Erfahrungen zur Zeit des Ersten Weltkrieges fußten, geplagt, zur Vorsicht neigte, und deshalb den ,indirekten Weg“ im Kampf gegen Hitler-Deutschland befürwortete und die Errichtung der zweiten Front im Westen verlangsamte. ${ }^{87}$ Das negative Churchill-Bild wurde nach dem Ende des Krieges vor allem von führenden Militärs genährt, die in ihren Memoiren einen Mann beschrieben, der mehr nach Stimmung und Intuition entschied, wie ein Spieler, der für diese Art des Handelns schon nach dem Gallipoli-Desaster mit ähnlichen Argumenten kritisiert worden war. ${ }^{88}$

Dabei stand er Landungsoperationen als solchen nicht zwingend feindlich gesinnt gegenüber. Allerdings vertrat er die Auffassung, dass große Landungsoperationen in der nahen Zukunft nicht durchführbar waren, weshalb er zu Beginn der 1940er Jahre nach Plänen für kleinere Operationen verlangte. Zudem war er der Überzeugung, dass großangelegte Luftangriffe auf Deutschland die beste Offensivoption gegen Nazideutschland darstellte. ${ }^{89}$ Es ist daher eine Fehlannahme, dass Churchill den ,indirekten Zugang“ befürwortet hätte und dass er eine strategische Ausrichtung auf das Mittelmeer hin einer zweiten Front in Frankreich vorgezogen hätte. Churchill agierte vielmehr im Rahmen der Möglichkeiten und wollte die Errichtung einer zweiten Front gegen ein zu starkes Deutschland vermeiden, da dieses Vorhaben sicherlich ähnlich desaströs hätte enden können, wie viele andere Operationen - etwa Dünkirchen - zuvor. Michael Howard wies schon 1968 in seiner Studie zur Mittelmeer-Strategie im Zweiten Weltkrieg darauf hin, dass Churchill keine Obsession für Nebenkriegsschauplätze besaß, sondern vielmehr bestrebt war, die Wehrmacht dort herauszufordern, wo britische Truppen eine Chance auf einen Sieg besaßen. ${ }^{90}$ Der britische Premierminister war folglich nicht gegen die Errichtung einer zweiten Front im Westen, er wollte diese nur zu den bestmöglichen Konditionen schaffen. Weder ging er von einem Kollaps der sowjetischen Truppen aus, noch glaubte er, dass die Landungen in der Normandie zu einem Desaster würden, so lange man nur den richtigen Moment gut genug vorbereitete. Dabei spielte sein Wunsch, die Initiative zu übernehmen, jedoch nicht immer für ihn, da ihm bisweilen die Unmöglichkeiten einiger der Nebenkriegsschauplätze verborgen blieben. ${ }^{91}$ Es kann aber davon ausgegangen werden, dass die relativ späte Schaffung einer zweiten Front als Folge großer alliierter Landungsoperationen in Frankreich im Juni 1944 nicht von Churchills angeblicher Furcht eines zweiten Gallipoli bestimmt war. Die Entwicklungen im

87 Ebd.

88 Ebd., S. 8.

89 Ebd., S. 8f.

90 Howard, Strategy, S. 31 f.

91 Baxter, Churchill, S. 10. 
Zuge der Planungen des D-Day waren wesentlich komplexer und sollen hier, um das Argument der Gallipoli-Angst zu entkräften, kurz zusammengefasst werden. ${ }^{92}$

Die Landung in der Normandie war eines der wichtigsten Ereignisse in der Geschichte des Zweiten Weltkrieges. In der Kontroverse, die sich in der Diskussion derselben entwickelte, nahm Churchill als britischer Premierminister nicht unvermutet eine zentrale Stellung ein, wobei ihm von sowjetischen und amerikanischen Militärs vorgeworfen wurde, er wäre gegen die Invasion von Westen gewesen, meist mit dem Hinweis darauf, er habe die Sowjetunion unter Stalin schwächen wollen. Dabei wurde vor allem über seine Operationswünsche im Hinblick auf das Mittelmeer spekuliert, diese seien nur gewählt worden, weil Churchill das Scheitern von großen Landungsoperationen, in der Tradition Gallipolis, sowie eine direkte Auseinandersetzung mit der Wehrmacht in Westeuropa fürchte. Tatsächlich aber war das Mittelmeer, nach dem Scheitern eines Eingreifens in Skandinavien und der scheinbaren Unmöglichkeit, ein vom ungeschwächten Deutschland verteidigtes Frankreich einzunehmen, die letzte Option für etwaige Interventionen. Darüber hinaus wichen Churchills Pläne kaum von denen seiner militärischen Berater ab. Neben einer Intensivierung der strategischen Bombardierung Deutschlands wurden vom britischen Premierminister die Eroberung Nordafrikas sowie die Invasion Siziliens als Ziele für Operationen im Jahre 1942 genannt und befürwortet. Dabei betonte Churchill später selbst, dass es einzig und allein eine großangelegte Landungsoperation wäre, die als entscheidende Maßnahme den Krieg beenden würde..$^{93}$

$\mathrm{Zu}$ Konflikten der politischen und militärischen Entscheidungsträger schien es unter anderem gekommen zu sein, da die amerikanische Seite unter der Führung von General George C. Marshall (1880 -1959) davon ausging, dass nur ein konzentrierter Großangriff in Europa die deutsche Herrschaft auf dem Kontinent beenden würde. In einem bereits 1941 begonnen „Siegesplan“ (Victory Plan) wies dessen Autor, Colonel Albert Wedemeyer (1897-1989) darauf hin, dass es keinen anderen Weg gäbe, als der deutschen Wehrmacht auf dem Kontinent mit einer überlegenen Landarmee entgegenzutreten. Dahingehend ging er von fast neun Millionen Soldaten in 200 Divisionen aus, wobei die Kräfte der Roten Armee zu diesem Zeitpunkt nicht berücksichtigt worden waren. Marshalls strategisches Konzept basierte eben auf diesen Annahmen, denen Churchills Wunsch nach kleineren Operationen an den geographischen Peripherien des europäischen Konfliktes zuwiderliefen. Darüber hinaus erschien den Amerikanern das westeuropäische Theater das am logistisch günstigsten gelegenste mit der kürzest

92 Die Darstellung folgt dabei, sofern nicht explizit anders ausgewiesen, Ben-Moshe (Churchill). 93 Churchill, Second World War, Bd. 3, S. 655. 
möglichen Route ins Herz der deutschen Industrieproduktion, dem Ruhrgebiet. Von der französischen Küste wäre ein Vorstoß dahin am einfachsten, weshalb der Fokus der US-Planer auf diesem Bereich lag, zumal die britischen Basen näher zu Nordfrankreich lagen als zu Nordafrika. Darüber hinaus gab es nur in Großbritannien ausreichend ausgebaute Häfen, um eine große US-Armee schnell und ohne großen Aufwand zu landen und im Falle der Invasion von dort nach Frankreich zu verschiffen. Hinzu kam, dass bei einem Angriff auf andere Ziele im Mittelmeer oder im Mittleren Osten immer noch die Versorgungslinie durch den Atlantik verteidigt werden müsste, wodurch zusätzliche Kräfte, ohne aktiv in das Kriegsgeschehen eingreifen zu können, gebunden gewesen wären.

Churchill hatte hingegen gute Gründe Marshalls Plan zunächst zu akzeptieren, denn die Verlagerung von US-Truppen nach Europa, erlaubte es ihm, freiwerdende britische Kräfte nach Belieben, notfalls auch ohne Zustimmung der Amerikaner, an den von ihm favorisierten Kriegsschauplätzen, also dem Mittelmeer und dem Mittleren Osten, einzusetzen. Zudem ging er auf Basis von Geheimdienstberichten davon aus, dass Deutschland in seinem Feldzug gegen die Sowjetunion 1942 so geschwächt wäre, dass eine großangelegte Landung in Frankreich schließlich durchaus den realen Möglichkeiten des Kriegsgeschehens entsprochen hätte. Während eines Besuches in Moskau im August 1942 versprach Josef Stalin (1878-1953) die Errichtung der „Zweiten Front“ im Folgejahr, wobei er nicht darauf hinwies, dass etwaige Verzögerungen möglich wären. Churchill selbst hatte zwei Dinge zu berücksichtigen: 1) Deutschlands Kapazitäten in der Verteidigung Frankreichs und 2) den Verlauf der Mittelmeeroperationen. Aufgrund beider Faktoren, war eine Verschiebung der Errichtung der „Zweiten Front“, selbst wenn die Amerikaner auf diese pochten, möglich, etwas, dass er Stalin jedoch so nicht kommunizierte. Das heißt allerdings nicht, dass er Stalin gezielt anlog und hoffte, eine „Zweite Front“ verhindern zu können, denn in seinen strategischen Überlegungen, und das bereits im Ersten Weltkrieg, hatte die Entsendung britischer Truppen nach Westeuropa eine unangefochtene Bedeutung.

Im Zuge der Casablanca-Konferenz im Januar 1943 konnte sich Churchill mit dem US-Präsidenten Franklin D. Roosevelt (1882-1945) darauf einigen, dass der nächste Schritt der vereinten Operationen die Invasion Siziliens sein würde. Geht man also von der These aus, Churchill habe aufgrund der Gallipoli-Erfahrung jedwede Form von Landungsoperationen abgelehnt, muss schon bei den Planungen für 1943 auffallen, dass er nicht von Dardanellen-Alpträumen heimgesucht wurde, sondern lediglich das Ziel Frankreich zu diesem Zeitpunkt ablehnte. Daneben wäre der Sieg im Kampf um den Atlantik eines der Hauptziele für 1943 gewesen, wobei die Bombardierungen deutscher Städte gleichfalls zu intensivieren wären. Ein spezifisches Datum für die Invasion Nordfrankreichs und die Schaffung der „Zweiten Front“ wurde nicht festgesetzt, da dieses immer noch, 
zumindest in Churchills Dafürhalten, vom Zusammenbruch der Wehrmacht abhing. Nach der Landung und Einnahme Siziliens folgte eine Diskussion über eine eben solche in Italien, wobei Marshall befürchtete, Truppen zu „vergeuden“ und den eigentlichen Plan der „Zweiten Front“ in Westeuropa weiter zu verlangsamen. Churchill, ebenso wie seine Stabschefs, argumentierte allerdings, dass der Angriff auf Italien nicht nur die Ostfront und damit Stalin entlasten würde, sondern gleichzeitig Kontingente, die normalerweise zur Verteidigung Frankreichs genutzt werden sollten, an einem anderen Schauplatz binden und damit die zukünftige Operation erst ermöglichen würde.

Als es um die konkreten Planungen zu den Landungen kam und erstmals britische Truppen aus Italien abgezogen wurden, gab Churchill in einem Treffen mit führenden Mitgliedern des Kriegskabinetts zu bedenken, dass er zwar nicht die Landungsoperationen per se skeptisch beurteile, sondern was danach passierte, wenn die Wehrmacht durch das alliierte Eingreifen auf anderen Schauplätzen noch nicht ausreichend geschwächt, die logistische Leistungsfähigkeit Deutschlands noch nicht ausreichend geschädigt wäre. Er machte deutlich, dass er der Operation Overlord nur unter bestimmten Konditionen zustimmen konnte und dass die Strategie der Amerikaner eine falsche sei. Nochmals wies er darauf hin, dass, wenn es nach ihm und den britischen Interessen ginge, zunächst Italien und dann der Balkan Ziele der alliierten Operationen sein müssten, bevor, und zwar erst nach einem Kollaps Deutschlands, an eine großangelegte Invasion in Frankreich zu denken war. Eine solche Strategie entsprach dem „Kind des Empire“ Churchill, der in erster Linie britische Interessen, nämlich im Mittelmeer und im Nahen Osten gesichert sehen wollte. Die Gefahr, dass die Amerikaner im Falle einer weiteren Verzögerung Truppen in den Pazifik verlagern würden, da es für sie entweder Westeuropa oder Südostasien, jedoch nicht um die Wahl zwischen Mittelmeer und Westeuropa ging, ließ den britischen Premierminister kalt, und er ließ die Amerikaner wissen, dass er einem Abzug aufgrund der strategischen Notwendigkeiten Großbritanniens in Europa zustimmen würde, sofern die bereits auf den britischen Inseln stationierten sechs US-Divisionen verblieben und der Aufbau amerikanischer Luftstreitkräfte in England fortgesetzt würde.

Ende 1943 musste Churchill in Teheran beim Treffen der „Großen Drei“ einlenken und schließlich einer Landung in der Normandie im Folgejahr zustimmen. Der britische Premierminister schien von der Idee, gegen ein nicht geschwächtes Deutschland in den Krieg ziehen zu müssen, geängstigt zu sein, etwas, das man durchaus mit dem Ersten Weltkrieg, allerdings nicht unbedingt mit Gallipoli in Verbindung bringen kann. Churchill war sich zwar bewusst, dass Overlord be- 
nötigt wurde, um die Front im Osten und damit die Sowjetunion zu entlasten, ${ }^{94}$ allerdings war der Preis einer solchen Operation gegen ein immer noch gefährliches Deutschland unberechenbar. Die Frage, warum Churchill also eine periphere Strategie dem gezielten Frontalangriff vorgezogen haben könnte, kann nicht wirklich einfach und sicherlich nicht monokausal beantwortet werden. $\mathrm{Zu}$ bemerken gilt, dass der britische Premierminister 1) die schweren Verluste, die aufgrund der Invasion in Frankreich und der anschließenden Auseinandersetzung mit Deutschland bevorstanden, fürchtete, dass er 2) sicherlich die Gefahr sah, dass die Sowjetunion nicht nur durch eine „Zweite Front“ entlastet, sondern zugleich als zu stark aus dem Konflikt hervorgehen könnte, was politisch nicht im Sinne Churchills sein konnte und 3) war er nicht überzeugt - und das kann durchaus, auch wenn es keiner Paranoia glich, als Erfahrungswert mit Gallipoli in Verbindung gebracht werden -, dass eine erfolgreiche Landung noch keinen Sieg gegen Hitlers Armeen darstellte, sondern dieser auf den Feldern und Straßen sowie in den Städten zwischen Normandie und Ruhrgebiet errungen werden musste.

In seiner eigenen Darstellung weist Churchill auf die Verluste des Ersten Weltkrieges hin, wenn er erklärt, warum ihm an einer möglichst späten Invasion gelegen war. ${ }^{95}$ Dadurch gibt er gleichwohl zu, dass er den Tod der sowjetischen Soldaten sowie der dortigen Zivilbevölkerung - ganz zu Schweigen von den Millionen in den Vernichtungslagern der Nazis systematisch ermordeten Juden -, dem der britischen Soldaten, die für ihn politisch bedeutsam waren, vorzog. Zudem hat Tuvia Ben-Moshe darauf hingewiesen, dass Churchill sicherlich nicht zu den Traumatisierten des Ersten Weltkrieges gehörte, selbst wenn er kurze Zeit an der Westfront verbracht hatte. Als Kriegsenthusiast, der, wie oben bereits beschrieben, der militärischen Auseinandersetzung gar eine gewisse Freude abgewinnen konnte, und als rücksichtslos agierender Politiker galt, war der britische Premierminister lediglich darauf bedacht, seine eigenen Ziele zu verfolgen und die lagen nun einmal nicht zu allererst in Frankreich, sondern im Mittelmeer und im Mittleren Osten. Dass Churchill große Verluste beinahe egal waren, zeigt schon sein Verhalten im Zuge der Operationen an den Dardanellen und auf der GallipoliHalbinsel, während derer er bereit war, höhere Verlustzahlen und gesunkene Schiffe in Kauf zu nehmen, so lange nur ein Erfolg verbucht werden konnte. Churchill, und das muss in aller Deutlichkeit gesagt werden, diente nämlich in erster Instanz sich selbst.

94 Colville, Fringes S. 463 u. S. 468.

95 Churchill, Second World War, Bd. 1, S. 384 u. Bd. 5, S. 582. 
In seiner Biographie des Duke of Marlborough (1650-1722) kritisiert er beispielsweise die Taktiken des ausgehenden 17. Jahrhunderts, die fast schon obsessiv darauf bedacht waren, Verluste zu vermeiden. ${ }^{96}$ Churchills eigenes strategisches Denken war in erster Linie eben nicht darauf ausgerichtet, Verluste zu vermeiden. Im Zuge der Gallipoli-Affäre hatte er aber erfahren, welche politischen Auswirkungen solche auf die eigene Karriere haben konnten. Persönlich schien ihn also der Tod von Soldaten nicht zu berühren, politisch betrachtet jedoch umso mehr. Dabei zählte für Churchill nicht nur die Politik, denn eine seiner lebenslangen Ambitionen hatte gerade darin bestanden, große Siege auf dem Schlachtfeld zu erringen, denn die politische Karriere sei wohl kaum mit militärischem Ruhm zu vergleichen. Dieser basierte auf Siegen und nicht auf gescheiterten Operationen, was Overlord hätte werden können. Insgesamt betrachtet hing Churchills Wunsch nach einer Verzögerung der Landungen in der Normandie also mit einer Vielzahl von Gründen zusammen - Interessen des Empire, Schwächung Stalins, eigene britische Strategie -, die sich aber schlussendlich alle auf einen Nenner bringen lassen könnten: Churchills persönliche Interessen. Wenn sich überhaupt eine Verbindung zu Gallipoli darstellt, dann die der Erfahrung was aus solchen, zunächst als unumgänglich geltenden Operationen erwachsen kann, nämlich der eigene politische Abstieg. Als Premierminister musste er diesen unbedingt verhindern.

Nachdem die Entscheidung aber unabwendbar geworden war, hätte fast niemand, so die bereits zitierte Brooke Allen, den sensationslüsternen Churchill davon abhalten können, die Invasionstruppen persönlich $\mathrm{zu}$ begleiten. ${ }^{97} \mathrm{Nach}$ dem Desaster von Gallipoli war es dem späteren Premierminister gelungen, zurück in die Politik zu gelangen, die er während des Zweiten Weltkrieges und darüber hinaus noch beeinflussen sollte. Die Erfahrungen, die er im Zuge der Dardanellen-Kampagne gemacht hatte, waren ihm in dieser Zeit geblieben, doch die Hoffnung, die schon 1915/16 enttäuscht worden war, schien zumindest teilweise nicht mehr zu existieren, oder wurde von einem stärkeren Realismus, der mit dem Alter in Churchills Bewusstsein Einzug gehalten haben könnte, kontrolliert.

Ungeachtet der Tatsache, dass Churchill als späterem Premierminister wohl die größte Aufmerksamkeit bei der politischen Diskussion um Gallipoli sowie den Langzeitfolgen für die Strategie des Zweiten Weltkrieges zugedacht worden ist, haben sich viele britische Historiker mit den meisten Facetten der Operation auseinandergesetzt und diskutieren seit nunmehr einhundert Jahren über die

96 Churchill, Marlborough, Bd. 2, S. 141.

97 Allen, Sum, S. 314. 
Frage, ob es tatsächlich möglich gewesen wäre, die Halbinsel einzunehmen und wenn ja, woran dieser Erfolg gescheitert war. Gallipoli ist deshalb im britischen Gedächtnis mehr als lebendig. Allerdings gibt es ein weiteres Land, in dem der Mythos um die Ereignisse von 1915/16 bis heute zu einem der wichtigsten Gedenkanlässe der kollektiven Erinnerung der Nation gehört: Australien.

\subsection{Australien}

Als 2002 der Tasmanier Alec Campbell im Alter von 103 Jahren verstarb, starb mit ihm der letzte lebende australische Gallipoli-Veteran. ${ }^{98}$ Das Begräbnis erweckte ein großes mediales Interesse, zumal selbst der Premierminister Australiens eine Chinareise unterbrach, um am Staatsbegräbnis des letzten Veteranen der Gallipoli-Kampagne teilzunehmen. Mehr als ein Jahrhundert bestimmte diese die Erinnerung des Landes an den Ersten Weltkrieg und schon während der Kampagne erreichte Australien der Ruf aus Gallipoli, dass dort das „unbezahlbare Blut unserer Söhne, Brüder, Väter, Liebenden, Freunde [...] auf dem Altar der Lust nach Macht und Weltherrschaft der Hunnen-Teufel geopfert" ${ }^{* 99}$ würde. Diejenigen, die dem Ruf zur Verteidigung der Menschlichkeit nicht Folge leisteten, waren als Verräter an ihren toten Kameraden, an ihrem Land, ja sogar der gesamten Menschheit $\mathrm{zu}$ betrachten. ${ }^{100}$ Und Tausende junger Männer folgten dem Ruf. Gallipoli wurde $\mathrm{zu}$ einem der wichtigsten Ereignisse in der Nationswerdung Australiens, das sich im Zuge des Großen Krieges ,australisierte“ und mehr und mehr von Großbritannien emanzipierte.

Durch die Operationen auf der Gallipoli-Halbinsel war diese von einer weitestgehend unberührten Landschaft am Ägäischen Meer in einen Kriegsraum verwandelt worden, in dem die Geographie nicht länger vom Menschen unangetastet blieb, sondern durch Grabenanlagen sowie Geschosseinschläge fundamental verändert wurde. ${ }^{101}$ Es gibt sicherlich viele Dinge, die nur unzureichend beschrieben werden können, solange der Ort nicht selbst besucht wurde, es ist jedoch sicher, dass der lange Aufenthalt, gerade im Falle der australischen Truppen zu einer gewissen Vertrautheit mit ihrer Umgebung führte, die durchaus als intim $\mathrm{zu}$ bezeichnen ist. ${ }^{102}$ In der nationalen Mythologie Australiens nimmt dieser Raum bis in das 21. Jahrhundert eine ganz besondere Stellung ein und ist

98 Fewster et al., Gallipoli, S. 1.

99 Nesbit, Call, S. 2.

100 Ebd., S. 4

101 Sagona u. Mackie, Introduction, S. 1.

102 Patel, Anzac, S. 53. 
einerseits aufgeladen von patriotischen Gefühlen und wird andererseits im öffentlichen Diskurs als ein historischer Ort erinnert, an dem die australische Nation ihren Zusammenhalt begründet hat. Diese national-patriotische Aufladung findet sich in fast allen Texten, die mit Blick auf Gallipoli innerhalb der nationalen Presse und Historiographie Australiens seit den Ereignissen selbst erschienen sind. ${ }^{103}$ Ohne Zweifel ist die Erfahrung Gallipolis also ein elementarer Bestandteil der australischen Nationalidentität, der von den Truppen ausging, die die Kampagne selbst erlebt hatten und im Anschluss daran zu gescheiterten Helden stilisiert wurden. ${ }^{104}$ Es waren die zerklüfteten Klippen und Hügel, die den „nobelsten Heldenmut" ${ }^{105}$ bei denen hervorgebracht hatten, die in diesem Kriegsraum zum Einsatz gelangt waren.

Des Weiteren war es die Erfahrung der Australier, so weit von zu Hause entfernt zu sein, in einem so feindseligen Gebiet, in dem sie zunächst durch ein unter Wasser mit Stacheldraht gesichertes Küstengebiet waten und den unaufhörlichen Salven der Artillerie sowie dem vernichtenden Feuer der Maschinengewehre versuchen mussten, zu entgehen, bevor sie sich schlussendlich nur vor dem Tod retten konnten, indem sie sich tief in die Landschaft eingruben. ${ }^{106}$ Es ist diese Bitternis der Landschaft von Gallipoli in Verbindung mit der steten Konfrontation von Leid und Tod, die die Erfahrung der australischen Soldaten bestimmte. Es ist das Überleben sowie das gemeinsame Entbehren, das die ANZAC-Truppen als Gemeinschaft in diesem spezifischen Raum und im Moment der Gallipoli-Kampagne zusammenschweißte. ${ }^{107}$ Dieses Erlebnis veränderte das australische Denken über den Krieg und transformierte eine Siedlungskolonie zu einer selbstbewussten Nation, deren Helden dem Britischen Empire bewiesen hatten, dass sie als ebenbürtig zu betrachten waren. ${ }^{108}$ Der nationalen Historiographie konnte nun ein Narrativ der Gewalt und des Krieges, aber auch der Niederlage hinzugefügt werden, wobei dieses einen durchaus egalisierenden Charakter besaß und die Kolonie auf eine Ebene mit dem Mutterland hob. Die ANZACs oder Gräber (Digger), wie sie genannt wurden, konnten folglich ein Teil der australischen Mythologie werden, wobei ihr Schicksal eng mit dem der Landschaft von Gallipoli selbst verknüpft blieb.

Dabei trugen die Soldaten selbst zur Schaffung dieses Mythos bei, denn viele von ihnen hatten Tagebücher und Gedichte verfasst sowie Bilder und Skizzen

103 Kirişci, Face, S. 174.

104 Rechniewski, l'Australie, S. $123 \mathrm{f}$.

105 Masefield, Gallipoli, S. 9.

106 Ebd., S. 9 f.

107 Carlyon, Gallipoli, S. 15; McCartney, Gallipoli, S. 104.

108 Die Darstellung folgt im Weiteren, sofern nicht anders angegeben Hoffenberg (Landscape). 
angefertigt. Etwa 150 Soldaten trugen ihr Material zum sogenannten ANZAC-Buch zusammen, das schon 1916 erschien, welches von Charles Bean (1879-1968), der als offizieller Historiker der ANZAC-Geschichte an der Entstehung des australischen Gallipoli-Mythos beteiligt war, herausgegeben wurde. ${ }^{109}$ Das Vorwort zu diesem Buch stammte von Birdwood, der darin erneut betonte, dass die „Tapferkeit unserer Männer“ den Landungsbereich der australisch-neuseeländischen Truppen historisch bedeutend gemacht hätten und dass die ANZAC-Bucht „für ewig eine geographische Landmarke bleiben wird. " ${ }^{110}$ Er sieht dabei den Wert des Buches vor allem darin, dass es, sofern es einmal in die „Hand unserer Kinder, oder unserer Kindeskinder fallen sollte, dazu dienen wird ihnen ein wenig davon zu zeigen, was ihre Väter für das Empire, und sicherlich für die Zivilisation getan haben“. ${ }^{111}$ Im ANZAC-Buch selbst werden die Eindrücke der Soldaten wiedergegeben. Es wird beispielsweise von der Landung und dem ersten Anblick der Bucht berichtet, aber auch Erfahrungen über erste Verwundungen oder den allgemeinen Kriegsalltag werden geteilt. ${ }^{112}$ Berichtet wird ebenfalls über die Fliegenplage sowie die Langeweile, die bisweilen nur durch das Rauchen der Soldaten unterbrochen werden konnte. ${ }^{113}$

Dabei beschrieben die Soldaten, ebenso wie die publizierten Memoiren und offiziellen Darstellungen der Kampagne die Gallipoli-Halbinsel so, wie einst der australische Kontinent selbst von Entdeckern und Kartographen geschildert worden war. Die Soldaten erblickten bisweilen auffallende Gemeinsamkeiten zwischen den Räumen ihrer Heimat und dem ihres Kriegseinsatzes, wobei letzterer nicht selten zum australischen Hinterland umgedeutet wurde. Diese Fantasien können verdeutlichen, weshalb die ANZAC-Tradition bis zum heutigen Tag so lebendig ist, denn die nationale Identität der Australier wurde unterbewusst auf den geographischen Raum Gallipolis projiziert. Dabei wird diese Tradition in Australien selbst, durch die jährliche Begehung des ANZAC-Tages am 25. April, also dem Jubiläum der australisch-neuseeländischen Landungen, begangen. Der Mythos, der damit verbunden ist, ist gewiss künstlich geschaffen worden. Darin werden die Heldentaten der jungen Männer, die weit entfernt der Heimat ihr Leben verloren hatten, zu Heroen nationaler Größe stilisiert. Nicht zu Unrecht ist der ANZAC-Mythos deshalb mitunter kritisch betrachtet worden. ${ }^{114}$ Es waren Vertreter des gesamten politischen und wirtschaftlichen Spektrums, die die Deutungsho-

109 Vgl. dazu Kent (ANZAC Book).

110 Birdwood, Introduction, S. ix.

111 Ebd., S. x.

112 Vgl. Man of the Tenth (Landing) und Colles (Beachy).

113 Vgl. dazu Garland (Nicotine) und Smith (Home).

114 Vgl. dazu Ross (Myth), Thomson (Shots) und Thomson (ANZAC Memories). 
heit der ANZAC-Erinnerung beanspruchten und deshalb bestrebt waren, aus dem einfachen australischen Soldaten einen Helden $\mathrm{zu}$ kreieren. Im Zuge dessen wurden Legendenbildungen, wie sie bereits von den Goldgräbern im Australien der 1850er Jahre entstanden waren, transformiert und entsprechend fortgesetzt. Oft wurden die Erfahrungen der Truppen mit denen der Australier im Outback gleichgesetzt und die klimatischen Parallelen dieser Leben miteinander verglichen.

Die Landschaft Gallipolis wurde folglich aus ihrem räumlichen und zeithistorischen Kontext entfernt, um in ein mythisches Gebilde eingefügt zu werden, bei dem nicht der Erste Weltkrieg oder der Angriff auf die osmanische Armee, sondern ganz klar die Erfahrung der australischen Soldaten im Mittelpunkt stand. Die Landschaft wurde damit automatisch zum Bezugspunkt des kollektiven Gedächtnisses und nationaler Geschichtstraditionen. Die Darstellungen des Ersten Weltkrieges integrierten Gallipoli, trotz der Tatsache, dass es sich um einen weit entfernten Ort in einem anderen Land handelte, in die nationale Perspektive des Großen Krieges und schufen dadurch einen geographischen Raum, der im kollektiven Gedächtnis mit einem gewissen Traumbild, gescheiterten Hoffnungen, aber auch nationaler Größe assoziiert werden konnte.

Dabei war die Landschaft von Gallipoli bestens geeignet, da sie doch demjenigen, der über sie las, zwangsläufig an Australiens Wüsten und Bergformationen erinnern konnte und damit auf präkonditionierte Erinnerungsmuster traf. Es fand folglich eine „Australisierung“, also kulturelle Aneignung fremden Territoriums statt. Das Schlachtfeld der Dardanellen-Kampagne konnte so als Fortsetzung der Besiedlung der australischen Wildnis verstanden und deshalb umso einfacher in die nationale Geschichtsschreibung integriert werden. Diese wurde im Zuge des Ersten Weltkrieges, der erstmals eigens aufgestellte und geführte australisch-neuseeländische Truppenkontingente ermöglichte, von der Ebene einer kolonialen auf die einer nationalen erhoben. Die ANZAC-Truppen setzten den Kampf ihrer Vorfahren in einer ähnlich gestalteten Landschaft fort und konnten deshalb den Anspruch auf nationale und unabhängige Größe erheben. Vermisste Soldaten und unbekannte Gräber fallen dabei ebenfalls in altbekannte Deutungsmuster, die bereits aus Australiens kolonialer Vergangenheit und Frühphase der Besiedlung bekannt waren.

Die Einsamkeit sowie die Angst in den Schützengräben spiegelte genau das wider, was viele der Soldaten aus Erzählungen ihrer Väter über das Leben im australischen Busch kannten. Ihre Partizipation an den Operationen bei Gallipoli gab ihnen das Gefühl, eine Erfahrung mit ihren Vorvätern zu teilen, von der sie bisher nur in Geschichten gehört hatten. Der ANZAC-Brückenkopf wurde somit zu einer neuen Kolonie transformiert, ein Spiegelbild alter Zeiten, in denen die Soldaten eben nicht nur gegen den Feind, sondern vor allem gegen die Widrig- 
keiten des Geländes anzukämpfen hatten. Der Kampf gegen die als „rassisch minderwertig“ betrachteten Ureinwohner wurde zum Kampf gegen den Osmanen, auf den man ebenfalls rassistisch aufgeladene Stereotype anzuwenden in der Lage war. In der Erfahrung der Landung, des Kampfes und des Begrabenwerdens konnten die jungen Australier folglich Anspruch auf ihre eigene, so weit entfernte Heimat erheben, etwas, das den australischen Nationalismus selbstverständlich stimulieren musste. Wenn John Masefield von den Soldaten wie von Helden der Antike spricht, dann trug er ebenfalls dazu bei, diesen Mythos zu befeuern. Tapferkeit und Männlichkeit, Heldenmut und Ideale wurden bemüht, um aus einfachen Männern eine Verkörperung des bewundernswerten ANZAC-Soldaten zu kreieren. Dieses Bild sollte so stark sein, dass es sich bis heute erhalten konnte.

Hinzu kommt eine andere Verbindung zwischen dem kollektiven Gedächtnis Australiens und der Gallipoli-Halbinsel. Viele Soldaten waren dort gefallen, doch deren Gräber waren nicht mehr zu identifizieren. Die Landschaft selbst verkörpert damit den letzten und unauffindbaren Hort der Gebeine derer, die dort gefallen waren. Gallipoli wurde so zu einem Ort des Gedenkens transformiert, an dem man die Größe Australiens spüren und die Erfahrung der Soldaten nachvollziehen konnte. Im Gegensatz zu anderen Gedenkstätten war diese besonders, war sie doch aus australischer Sicht auf der anderen Seite der Welt. Für viele blieb Gallipoli also lange ein unerreichbarer Ort, von dem nur Geschichten gehört oder gelesen werden konnten und der dadurch mit einer Vielzahl von Erwartungen behaftet wurde. Für diejenigen, die Gallipoli besuchen wollten, ergab sich also zunächst ebenfalls eine anstrengende Reise, die beinahe einen spirituellen Charakter, gleich einer Pilgerfahrt, annehmen konnte. Im Gegensatz zu den Soldaten 1915 endete die Reise nicht mit einer gefährlichen Landung und möglicherweise dem Tod, sondern für den Besucher mit einer Spurensuche innerhalb der eigenen nationalen Geschichtstradition.

Der Mythos steht gleichfalls in Verbindung mit einer kulturellen Entkolonisierung, einer Loslösung vom Britischen Empire durch die Etablierung eines eigenen nationalen Mythos, in welchem sich die Selbstwahrnehmung als Australier, nicht länger als kolonialer Untertan, zu verändern in der Lage war. Gallipoli wird deshalb zu einem Beleg einer nicht-britischen Vergangenheit, sozusagen zum wirklichen Beginn der australischen Unabhängigkeit. Wie in anderen nationalen Kontexten - USA oder Südafrika - auch, wurde ein Krieg und der mit diesem verbundene Schauplatz zur Geburtsstunde nationaler Identität erhoben. Die Symmetrie zwischen diesem Schauplatz und dem eigentlichen Heimatland ermöglichte es, die geographische Entfernung, die Fremdheit suggerierte, zu überwinden, und eine Spiegelung der eigenen Geschichte zu erreichen. Der Erste Weltkrieg hatte dadurch nicht nur eine genuin australische Militärtradition begründet, sondern einen Erinnerungsort, mit dem sich das kollektive Gedächtnis 
identifizieren wollte und konnte, geschaffen. In Analogie zur Kontinuität der eigenen Vergangenheit wurde Gallipoli von einem entfernten Kriegsschauplatz zu einem Symbol nationaler Erinnerung transformiert. Die Beschreibungen der Soldaten selbst, der Kriegsberichterstatter sowie der späteren Historiographen der Ereignisse trugen ihr Übriges dazu bei, den ANZAC-Mythos zu festigen und ihn bis heute am Leben zu erhalten.

Bereits in den frühen 1920er Jahren hatte die australische Regierung eine Mission auf die Gallipoli-Halbinsel gesandt, um verbliebenes Material und Relikte im ANZAC-Landungsabschnitt zu bergen, damit diese in einer Erinnerungsstätte in Australien konserviert werden könnten. ${ }^{115}$ Darüber hinaus wurden bis Ende 1924 alle Gräber der Soldaten, deren Name bekannt waren, markiert und die Namen derer, die nicht identifiziert werden konnten, wurden auf Erinnerungstafeln genannt. Bei Kap Helles war ein Monument für die Gefallenen der südlichen Landungsabschnitte errichtet worden, das australische hingegen an dem Standort, der als „Einsame Pinie“ (Lone Pine) bekannt war. ${ }^{116}$ In Canberra sollte später das Australian War Memorial (AWM) errichtet werden, dessen Artefakte-Sammlung auf dem beruhte, was Bean und seine Begleiter während ihrer Mission bergen konnten. Dort sollte die Erinnerungen an diejenigen, die weit entfernt von ihrem Vaterland, für eben dieses gefallen waren, erhalten werden. ${ }^{117}$ Das AWM spielt gegenwärtig eine nicht zu unterschätzende Rolle bei der Konservierung des Gallipoli-Bildes und der Bewahrung des kollektiven Gedächtnisses an die Ereignisse von 1915/1916. ${ }^{118}$ Die Aufopferung der eigenen Soldaten und die Niederlage von Gallipoli spielen in dieser Konzeption eine besondere Rolle und es ist die Aufgabe des AWM, diesen Helden der Vergangenheit eine transzendente Stimme im Gedächtnis der nationalen Gesellschaft zu bewahren. ${ }^{119}$ Wenn die Rolle der Australier und Neuseeländer bei der Besprechung von Gallipoli einmal nicht ausreichend erwähnt wurde, dann konnte das zum Beispiel zu einer heftigen Kritik der Veteranen führen, die sich nicht ausreichend wahrgenommen und gewürdigt fühlten. ${ }^{120}$ Bis heute hat Gallipoli seinen hohen Stellenwert nicht einge-

115 Bean, Gallipoli, S. 5.

116 Ebd., S. 341.

117 Ebd., S. 346.

118 Vgl. dazu Virgili (Australian War Memorial).

119 Taussig, Hero, S. 111-113.

120 Monro, Gallipoli, S. 648. 
büßt, obwohl die Generation derjenigen, die die Ereignisse selbst miterlebt haben, nicht mehr existiert. ${ }^{121}$

Es ranken sich immer noch zahlreiche Mythen und Legenden um die Halbinsel, auf der so viele Australier ihr Leben eingebüßt hatten. ${ }^{122}$ Im Frühjahr wird Gallipoli jedes Jahr von Touristen eingenommen, von denen bis zu 15.000 an den Messen und Feierlichkeiten zur Erinnerung an die ANZAC-Truppen teilnehmen. ${ }^{123}$ Was genau diese Landschaft für die Besucher bedeutet, lässt sich oft nicht genau erklären und eine solche Erklärung rangiert sicherlich jenseits der Vernunft. ${ }^{124}$ Für viele ist dabei die offizielle Geschichte Gallipolis nicht entscheidend, sondern das, was sie selbst darin sehen wollen. Wie ihre Vorfahren identifizieren sich viele der Besucher mit dem fremden Raum, der sich aufgrund der mythischen und nationalistischen Aufladung schnell zu eigen gemacht werden kann, von dem quasi in kultureller und memorativer Hinsicht Besitz ergriffen wird. Dabei ist ebenfalls schwer zu erklären, weshalb es gerade dieser Ort ist. So war doch Gallipoli nicht die schwerste Niederlage der Australier während des Ersten Weltkrieges, denn 1916 waren auch beinahe 30.000 Verluste bei Schlachten in Frankreich, z.B. Fromelles, zu verzeichnen gewesen. Doch im Gegensatz dazu blieb Gallipoli besonders, vielleicht gerade weil hier der ultimative Beweis der australischen Männlichkeit und des Rechtes der Nation auf ihre Existenz bewiesen worden wäre. ${ }^{125}$ Solche romantisierenden Narrative des Ersten Weltkrieges sind in letzter Zeit allerdings zu Recht kritisiert worden. ${ }^{126}$

Leslie Allen Carlyon bringt es auf den Punkt, wenn er schreibt, dass „der Sirenengesang dieses Strandes wenig mit Fakten oder der anerkannten Meinung der trockenen Fußnoten von Akademikern zu tun. Dieser wurzelt im Mythos, der Nostalgie - und der Imagination. Jeder der hierher kommt versucht Bilder auf eine leere Landschaft $\mathrm{zu}$ zeichnen“127 $\mathrm{um}$ den historischen Zustand wiederherzustellen. Wenn junge Australierinnen und Australier auf die Halbinsel kommen, um ein bis zwei Tage dort herumzuwandern, dann vor allem, weil sie auf der Suche nach ihrer eigenen Vergangenheit sind. Gallipoli wird dadurch zu einem „Land der

121 Der letzte ANZAC-Veteran, Alexander Campbell (1899-2002), der an den Operationen auf der Gallipoli-Halbinsel teilgenommen hatte, starb, wie oben erwähnt, im Mai 2002. Vgl. dazu Shaw (Alec Campbell).

122 Hart, Gallipoli, S. 452-462.

123 Carlyon, Gallipoli, S. $18 \mathrm{f}$.

124 Ebd., S. 19.

125 Ebd.

126 Vgl. Hopkins-Weise (Brothers).

127 Carlyon, Gallipoli, S. 20. 
Gedanken“128, welches Teil eines nationalen Selbstfindungsprozesses war, ist und vermutlich weiterhin sein wird. Dabei wird die Geschichte ganz individuell interpretiert, zum Teil auch fortgeführt, da die Touristen das erreichen, was den ANZAC-Soldaten verwehrt geblieben war: die Erkundung der Halbinsel.

Für Türken und Australier gleichermaßen ist Gallipoli dabei eine ehrenhafte Geschichte von Soldaten, die sich gegenüberstanden, zwar im Krieg, aber doch ohne die Gräuel und Schrecken, wie spätere Ereignisse und Kriege sie zeitigen würden. Hier gab es keine Massaker, keine schlechte Behandlung Kriegsgefangener, sondern nur zwei Kollektive, die sich in einem ehrenhaften Kampf zu übertreffen suchten - so zumindest in der romantisch verklärten Geschichte Gallipolis aus dem Blickwinkel der Touristen. Die Nachfahren derer, die das erlebt haben, können heute miteinander über die Ereignisse reden, ja sogar scherzen. Gallipoli wird zu einem Ort der Begegnung, allerdings einer friedlichen und auf Augenhöhe.

50 Jahre nach den Ereignissen der Gallipoli-Kampagne wurde das ANZACGebiet in die Türkischen Nationalparks integriert und 1973 wurde der Historische Gallipoli-Halbinsel Nationalpark errichtet und in die UN-Liste von Nationalparks und geschützter Regionen aufgenommen. 1996 bestand der Park aus fast 6.000 Hektar, allerdings lagen noch viele Gebiete, in denen 1915 und 1916 gekämpft worden war, außerhalb der Parkgrenzen. Deshalb wurde im gleichen Jahr der Gallipoli-Halbinsel Friedenspark eröffnet, dessen Grenzen schließlich 33.000 Hektar umfassten. ${ }^{129}$ Von den 39 türkischen Nationalparks ist der von Gallipoli einer der wichtigsten, da er vermutlich die meisten internationalen Touristen anzieht, wobei die weitere Entwicklung von den Ereignissen nach dem Putschversuch und der Radikalisierung unter der Regierung Erdogan abhängen dürfte. Mustafa Kemal hatte als Gründer der modernen Türkei dafür Sorge getragen, dass auf der Gallipoli-Halbinsel Monumente für die Gefallenen des Osmanischen Reiches errichtet wurden. Insgesamt wurde sichergestellt, dass aller knapp 200.000 Gefallenen ausreichend gedacht werden konnte. Besonderes Interesse am Gallipoli-Nationalpark hatten diejenigen, die auf den Spuren der DardanellenKampagne wandeln, die Natur der Halbinsel bewundern, oder an den Gedenkfeiern am 18. März, 25. April und 10. August teilnehmen wollten. Zwischen 1994 und 2004 war die Zahl der offiziell zählbaren Touristen, die dazu auf die Halbinsel gereist waren von ca. 100.000 auf 230.000 angestiegen. Die Parkleitung geht davon aus, dass in den ersten zehn Jahren des Bestehens etwa eine Million

128 Ebd., S. 21.

129 Cameron u. Donlon, Survey, S. 133; Kelkit / Celik / Eşbah, Ecotourism, S. 563. 
Touristen die historische Stätte besucht hätten. ${ }^{130}$ Diese würden die Möglichkeiten, die Gräben und Verteidigungsanlagen selbst besuchen zu können, begrüßen, und zahlreiche historische Artefakte seien noch immer in den Höhenzügen und den verschiedenen Verteidigungsanlagen zu finden. Zudem können die Kriegsgräber sowie die Monumente zur Erinnerung an die Ereignisse besichtigt werden. Neben den 33 Erinnerungsstätten der Alliierten sind gleichfalls 47 türkische Monumente für die Besucher zugänglich. ${ }^{131}$ Die steigenden Touristenzahlen führten zu einem Ausbau der lokalen Infrastrukturen, die die Ursprünglichkeit des Gebietes und die Erhaltung der historischen Anlagen zunehmend erschwert. Speziell zu den Gedenkfeiern steigen die Touristenzahlen extrem an, sodass die vorhandene Infrastruktur nicht immer ausreicht, um beispielsweise alle Gäste zu beherbergen. Nahmen beispielsweise 1999 nur 8.500 Menschen am ANZAC-Tag, also dem 25. April, an den Feierlichkeiten teil, so waren es 2002 schon über 15.000 , 2005, zum neunzigjährigen Jubiläum sogar mehr als 20.000. ${ }^{132}$ Erstaunlich ist dabei, dass vor allem junge Australierinnen und Australier $\mathrm{zu}$ den Besuchern gehören und das obwohl die Erinnerungsstätten aus australischer Perspektive nicht gerade einfach $\mathrm{zu}$ erreichen sind. Es scheint sich folglich um eine Erscheinung zu handeln, die gerade mit der jungen Generation der „Backpacker“ verbunden ist. Es soll deshalb kurz analysiert werden, was sich diese von einer solchen Reise erhofft und wodurch sie zu derselben motiviert wird.

Normalerweise werden gerade junge Menschen eher selten mit historisch erinnernden und patriotisch aufgeladenen Zeremonien in Verbindung gebracht. Und doch waren es gerade diese jungen Menschen, die als erste mit ihren Rucksäcken in großen Zahlen über die Halbinsel wanderten, um ein Stück ihrer eigenen Vergangenheit zu ergründen. ${ }^{133}$ Bei australischen und neuseeländischen Touristen hat Gallipoli einen besonderen Stellenwert und ist das Schlachtfeld des Ersten Weltkrieges, das von dieser Touristengruppe am häufigsten frequentiert wird. Eine besondere Rolle für das kollektive Gedächtnis dieser Gruppe spielt dabei die Rezeption Gallipolis als einer Art „heiliger Stätte“. Die Reise per se wird dabei zu einer Pilgerfahrt an einen entfernten Ort, der innerhalb der eigenen Gesellschaft, also gerade wegen des immer noch bestehenden ANZAC-Mythos eine ganz eigene Bedeutung erhalten hat. Die Erkundung der Gallipoli-Halbinsel wird also zur sakralen Erfahrung eines historischen Ereignisses, bei dem der Besucher mit der eigenen Vergangenheit, der eigenen Geschichte in Verbindung

130 Ebd., S. 566.

131 Ebd.

132 Cameron / Donlon, Survey, S. 133. West, Pasts, S. 261 nennt sogar eine Zahl von 30.000. 133 Ebd. 
treten kann. ${ }^{134}$ Archäologische Grabungen im Jahr 2003 haben gezeigt, dass das Schützengrabensystem immer noch existiert, dass Verteidigungslinien und -stellungen folglich noch klar zu identifizieren sind. ${ }^{135}$ Die historische Erfahrung wird dadurch für die Besucher ganz real greifbar und vor allem nachvollziehbar. Die ANZAC-Landezone wird von den Besuchern als kulturelles Erbe der eigenen Nation wahrgenommen und das obwohl sie sich außerhalb der nationalen Grenzen befindet. Durch ihre Wanderung über die Insel setzen sie die Aufgabe ihrer historischen Vorgänger fort, und durch diese beinahe sakrale Erfahrung, vollenden sie, was ihren Vorfahren verwehrt geblieben war: über die Grenzen des ANZAC-Gebietes hinaus vorzustoßen. Die Unvollkommenheit der Operation, die durch die Evakuierung der Truppen zur Realität geworden war, wird demnach postum aufgehoben und die historische Aufgabe zum Abschluss gebracht.

Natürlich trifft diese Erfahrung nicht auf jeden Touristen zu und die Popularität solcher Reisen nach Gallipoli war nicht immer so stark wie seit den 1990erbzw. 2000er-Jahren. Als die Anti-Kriegsbewegung in den 1970er-Jahren aktiv war, reisten wesentlich weniger Menschen - bedingt sicherlich durch andere Konditionen für solche internationalen Reisen - nach Gallipoli. In den 1990er-Jahren kehrte sich dieser Trend um und es nahmen auch wieder mehr Besucher an den nationalen Gedenkfeierlichkeiten des 25. April in großen australischen Städten wie Melbourne teil. Dieses erneuerte Interesse geht in erster Linie auf die 75-JahrFeiern des Jahres 1990 zurück. Die australische Regierung hatte für ausgewählte Gruppen militärischer, politischer und ziviler Repräsentanten sowie für Veteranen Reisen nach Gallipoli organisiert, das wachsende Interesse fand also ebenfalls einen Ausdruck in den Maßnahmen der Politik, um die Kampagne im kollektiven Gedächtnis am Leben zu erhalten. Zudem hatte die australische Regierung ein Interesse daran, die Zugänglichkeit zur ANZAC-Bucht für Touristen zu erhöhen und bat die türkische Regierung im Zuge der Vorbereitungen der Feierlichkeiten 2005 darum, die vorhandenen Straßenverbindungen in dieses Gebiet auszubauen. ${ }^{136}$ Im Zuge der Hundertjahrfeier 2015 waren erneut viele Tausende Menschen nach Gallipoli gepilgert, um an den Gedenkfeiern teilzunehmen.

Das zunehmende Interesse hatte die Gallipoli-Forschung stimuliert, sodass seit den 1990er-Jahren wieder verstärkt zu dieser Thematik gearbeitet wurde. Durch die Pilgerreisen vieler Australier entstehen aber auch ganz andere, alternative Gallipoli-Narrative, die von denen, die selbst die historischen Örtlichkeiten besucht hatten, an Freunde und Bekannte zu Hause tradiert wurden. Während die

134 Ebd., S. 259.

135 Cameron u. Donlon, Survey, S. 131.

136 Ebd., S. 135; West, Pasts, S. $261 \mathrm{f}$. 
Rolle der osmanischen Seite lange Zeit marginalisiert worden war, war im Narrativ der Touristen, in Interaktion mit den türkischen Guides vor Ort ein dialogischer Ansatz der historischen Interpretation entstanden, in dem die Erinnerungen und Geschichten der ehemals feindlichen Seite Einzug hielten. Natürlich haben nicht alle Rucksacktouristen ein Pilgerziel vor Augen, wenn sie nach Gallipoli reisen, da viele einfach von anderen Touristenzielen anreisen, um die Gelegenheit zu nutzen, während einer Europareise die Halbinsel noch einmal besucht zu haben. Viele dieser Trips sind folglich nicht geplant, sondern entwickeln sich eher spontan, wobei viele Touristen nach der Erkundung der Insel von einer historischen Ergriffenheit berichten, die sie so gar nicht erwartet hatten. Durch derlei Berichte werden in der Folge andere Touristen auf das Ziel aufmerksam und begeben sich in zweiter Instanz gezielter nach Gallipoli, um durch die geteilte Erfahrung, ähnlich den ANZAC-Soldaten während des Ersten Weltkrieges, Teil eines imaginierten Kollektivs zu werden. ${ }^{137}$ Dieses wird bisweilen auch noch auf der Leinwand beschworen, wenn der historische Stoff für das Kino aufgegriffen und die australische Perspektive, beispielsweise in Peter Weirs Gallipoli (1981) mit Mel Gibson oder zuletzt Russel Crowes The Water Diviner (2014), besonders betont wird. Doch nicht nur für Australien hatten die Ereignisse einen identitätsstiftenden Charakter.

\subsection{Türkei}

Das Osmanische Reich hatte im Vergleich zu anderen Schlachten des Ersten Weltkrieges in der Schlacht um die Gallipoli-Halbinsel - in der Türkei als Schlacht von Çanakkale bekannt - die höchsten Verlustzahlen zu beklagen. Gerade im post-osmanisch-türkischen Kontext kann daher der Stellenwert der Ereignisse zwischen April 1915 und Januar 1916 nicht hoch genug angesetzt werden. Es ist ein entscheidender Punkt in der historischen Entwicklung des Landes und der osmanische Sieg bei Gallipoli bildete später die Basis für die nationaltürkische Rhetorik seit den 1920er Jahren. ${ }^{138}$ Gerade weil das Osmanische Reich in den Jahren vor dem Ersten Weltkrieg, etwa in den Balkankriegen, Territorien eingebüßt und selten Siege vom Schlachtfeld zu vermelden hatte, war die Erfahrung, die Alliierten Truppen daran gehindert zu haben, die Gallipoli-Halbinsel einzunehmen, so bedeutend. Die Australier, die bis dahin kaum etwas über das Os-

137 Ebd., S. 262.

138 Fewster et al., Gallipoli, S. 6f. Sofern nicht anders vermerkt folgt die weitere Darstellung Fewster et al. (Gallipoli). 
manische Reich wussten, nahmen die Kampagne und den damit verbundenen Krieg in soldatischer Romantik wahr, im Zuge derer ein Tod zwar als „glorreich, aber vermutlich unwahrscheinlich"139 betrachtet wurde. Für die osmanischen Verteidiger war die Situation eine andere. Unter der Führung ausländischer Befehlshaber sollten sie gegen einen Feind antreten, von dem sie nichts wussten und den sie für etwas töten sollten, das sie selbst politisch kaum interessierte. Im Zuge der Ereignisse wuchs ihr Nationalismus, der vor allem durch die Führung charismatischer Führungspersönlichkeiten wie Mustafa Kemal stimuliert wurde, zu denen die Verteidiger der Halbinsel aufschauen konnte. Das Heimatland musste um jeden Preis gegen die herannahenden Scharen des Britischen Empire verteidigt werden. Die Wahrnehmung auf osmanischer Seite war deshalb eine gänzlich andere, als das von den Truppen des Britischen Empire antizipiert worden war, denn diese verstanden sich selbst als eine Art „Befreiungstruppe, die kam um den Osmanen eine Lektion zu erteilen oder sie von ihren deutschen Lehensherren $\mathrm{zu}$ befreien." ${ }^{140}$

Die heftigen und unnachgiebigen Angriffe der osmanischen Soldaten sorgten bald für Ehrfurcht und Anerkennung des Gegners, der mehr und mehr als Leidensgenosse und weniger als Feind angesehen wurde, denn auch die Soldaten der Armee des Osmanischen Reiches mussten die Hitze, die Fliegen, die Krankheiten und die ständige Gegenwart des Todes ertragen. Dabei erging es ihnen ob der spärlichen Rationen, die kaum mehr als kalten Bulgur beinhalteten, noch schlechter als den britischen und französischen Truppen. Viele der osmanischen Soldaten waren Rekruten aus ländlichen Regionen des Reiches, vor allem dem östlichen Anatolien, die auf die Halbinsel geschickt wurden, um ein politisches Relikt zu verteidigen, dessen Bedeutung sich ihnen häufig nicht erschließen mochte. Dabei waren die Männer oft sehr jung und wurden in ihren Dörfern aufgrund ihrer Arbeitskraft in der Erntesaison gebraucht, weshalb nicht wenige der Rekruten desertierten und sich auf den Weg zurück in ihre Heimat machten. Viele aber kehrten nie wieder zurück und ihre Gebeine würden, wie die der Gefallenen Briten, Australier, Neuseeländer, Inder, Gurkhas oder Maori in Massengräbern unter der Sonne, die auf die Halbinsel schien, verscharrt werden. Der Krieg hatte wahrlich nur wenig Raum für Heldentum, und doch schuf er auf der Seite der Osmanen einen Mythos, der seine volle Bedeutung erst in der Geschichte des türkischen Nationalstaates entfalten sollte: Mustafa Kemal.

Die Presse im Osmanischen Reich war während des Ersten Weltkrieges, wie in vielen anderen der kriegführenden Staaten auch, zensiert und es wurde versucht, 
jeden noch so kleinen militärischen Erfolg propagandistisch auszuschlachten, wohingegen Niederlagen oft gar keine Erwähnung fanden. In der Hauptstadt des Reiches lief das Leben zudem, wenn man einmal von einigen Angriffen britischer U-Boote im Schwarzen Meer absieht, meist ungestört weiter. Die Schlacht um die Gallipoli-Halbinsel bedingte nicht nur eine Stärkung des osmanischen, später türkischen, Selbstvertrauens, sondern generierte mit dem Helden Mustafa Kemal eine der einflussreichsten Persönlichkeiten der türkischen Geschichte. Während der Kampfhandlungen zeichnete dieser sich als einer der entscheidenden Offiziere aus, der nicht nur die ihm untergebenen Soldaten, sondern auch den Nationalstolz aller Osmanen mobilisieren konnte. Mehrmals war es sein persönlicher und unablässiger Einsatz, der über den Unterschied zwischen Sieg und Niederlage entschied. Kemal selbst bewertete die Zurückschlagung des Feindes am 26. April zwar nicht als Heldentat, aber immerhin stellte er fest, dass „es ein wichtiger Tag war, der dank der Entschlossenheit und der Beharrlichkeit der Truppen sowie der Tapferkeit und Bestimmtheit unserer Offiziere und Kommandeure gewonnen wurde. “141 Die besagte Tapferkeit sowie die Selbstaufopferung der osmanischen Soldaten wurde darüber hinaus auch von den deutschen Kommandeuren, deren Sicht auf die Ereignisse oben bereits geschildert wurde, wohlwollend wahrgenommen.

Bei der Verteidigung der Stellungen im Zuge der britischen Suvla-Landungen zeigte Kemal erneut große Initiative, die vom deutschen Befehlshaber von Sanders dahingehend gewürdigt wurde, dass er dem osmanischen Offizier große Zugeständnisse machte und ihm die Alleinverantwortung zur Verteidigung übertrug. Die osmanische Gegenoffensive am 9./10. August beendete schließlich nicht nur alle britischen Ambitionen auf der Halbinsel, sondern markierte gleichzeitig den Beginn der Legendenbildung um den späteren türkischen Präsidenten. Darüber hinaus war aus einer ungleichen, von Rassismus und Stereotypen geprägten Feindschaft auf beiden Seiten, eine, soweit das in einer Kriegssituation überhaupt möglich ist, wohlwollende Anerkennung auf Augenhöhe geworden. Kevin Fewster, Vecihi Başarin und Hatice Hürmüz Başarin sprechen gar von einer „Freundschaft“142, wobei hier doch darauf hingewiesen werden sollte, dass Freunde sich nur selten willentlich töten. Als die alliierten Truppen im Januar 1916 schließlich abgezogen waren, konnten die osmanischen Soldaten nach Monaten des Leids und Verlusts endlich die wohlverdienten Früchte ihres Sieges ernten und die heimatlichen Strandabschnitte erneut in Besitz nehmen. Dieser Prozess glich einem Festakt, besonders, da die britischen Truppen unter anderem

141 Ebd., S. 76.

142 Ebd., S. 119. 
Fleisch, Tee und Zucker zurückgelassen hatten und noch Wochen später konnte man Soldaten beobachten, die einen komisch anmutendes Potpourri aus osmanischen, britischen und australischen Uniformen trugen.

Der Sieg bei Gallipoli stimulierte ein Hochgefühl, dass verdientermaßen lange anhielt, denn die Bedeutung dieses militärischen Sieges konnte 1916 gar nicht hoch genug geschätzt werden, gerade wenn es um die Selbstdarstellung des Osmanischen Reiches ging. Der „kranke Mann am Bosporus“ hatte das große britische Empire auf dem Schlachtfeld besiegt, etwas, das auch in anderen Teilen des Weltreiches der Briten für Komplikationen sorgen konnte. Für Mustafa Kemal, der am 29. Oktober 1923 schließlich zum ersten Präsidenten der Türkei gewählt wurde, stellte der Erfolg bei den Dardanellen den initialen Punkt seiner politischen Laufbahn dar, konnte er sich zukünftig doch stets auf die erfolgreiche Verteidigung des Vaterlandes berufen.

Liman von Sanders missfiel, dass Kemals Rolle im Zuge der Gallipoli-Kampagne derart betont wurde. An Carl Mühlmanns Buch Der Kampf um die Dardanellen (1927) gefiel ihm besonders, „dass [es] die Tätigkeit Mustapha Kemal's der Wirklichkeit entsprechend geschildert habe, ohne auf die türkischen Übertreibungen und Unwahrheiten einzugehen. Insbesondere die Platzierung und Leitung der gesamten Artillerie im Anaforta-Abschnitt war ganz allein deutsche Arbeit. “143 Den diplomatischen Umgang mit dem osmanischen Kriegsminister Enver und der Marine, mit der der Chef der Militärmission ebenfalls aneinander geraten war, konnte Liman von Sanders seinem früheren Adjutanten Mühlmann, der ja nun im Sinne des Reichsarchivs schrieb, wo er mittlerweile beschäftigt war, nachsehen. ${ }^{144}$ Ersterer erhoffte sich jedenfalls einige Klarstellungen, wenn es um den Beleg deutscher Leistung im Zuge der Gallipoli-Kampagne und die „Klarstellung der damaligen Befehlsverhältnisse“ ${ }^{145}$ ging.

Trotz der Verstimmung auf Seiten des ehemaligen Oberbefehlshabers bei der Verteidigung der Gallipoli-Halbinsel, war die Kemal-Legende eng mit dem Sieg gegen die Alliierten 1915/16 verbunden. In den folgenden Jahren, in denen sich der spätere Präsident der Türkei nicht nur gegen innenpolitische Gegner, sondern auch Bedrohungen von außen behaupten konnte, taten ein Übriges, um die beinahe mythische Überhöhung des initialen Sieges türkischer Waffen, der sich im Zuge des Krieges in ähnlicher Weise nicht wiederholen sollte, weiter voranzutreiben. Der Aufstieg Kemals zum Vater der türkischen Nation war unaufhaltsam

143 Liman von Sanders an Carl Mühlmann, München, 30. Januar 1927, BArch MArch RH61/1088. 144 Fewster et al., Gallipoli, S. 119.

145 Liman von Sanders an Carl Mühlmann, München, 21. Juli 1927, BArch MArch RH61/1088. 
und blieb auf ewig mit dem Sieg bei Gallipoli verbunden, auch wenn dieser von Atatürk selbst nicht als wesentlich betrachtet worden war.

Es war die Schlacht von Gallipoli, die es ermöglichte, sich auf ein erfolgreiches Ereignis, das den Aufstieg des Offiziers zum Staatspräsidenten begründete, zu berufen. Sobald der Abzug der alliierten Streitkräfte von der Halbinsel abgeschlossen worden war, wurde Gallipoli zu einem Synonym für die Demütigung des Britischen Empire und zu einem Erfolg der osmanischen Armee sowie der türkischen Nation, wie sie seit den frühen 1920er Jahren vor allem von Atatürk ${ }^{146}$ selbst beschworen und in ihrem Narrativ gefestigt wurde. ${ }^{147}$ Die Siege von Gallipoli und der schlussendliche Erfolg im türkischen Unabhängigkeitskrieg (1919-1922), der mit der Anerkennung der Türkei als unabhängigem Staat im Vertrag von Lausanne 1923 endete, bildeten die Basis für die Nationswerdung unter Führung Atatürks. Allerdings besaß letzterer in der Erinnerungspolitik des Landes sicherlich mehr Gewicht als der Erfolg der osmanischen Armee 1916. ${ }^{148}$

Und doch ragt Gallipoli aus den für das Osmanische Reich sonst oft so desaströsen militärischen Ereignissen des Ersten Weltkrieges heraus. Die Armee war zwar nach den Balkankriegen, wie oben bereits beschrieben, im Zuge der deutschen Militärmission durchaus bereits modernisiert worden, ${ }^{149}$ in den Kriegsjahren offenbarten sich aber zahlreiche Probleme, so etwa mit der Infrastruktur des Reiches, dessen Limitiertheit die Handlungs- und Bewegungsfreiheit der Armee oft einschränkte, oder Krankheiten, wie etwa Typhus, der etliche Soldaten und Offiziere zum Opfer fielen. ${ }^{150}$ Ungeachtet solcher strukturellen Probleme hatte der Krieg jedoch den Einfluss des Staates vorangetrieben und zentralisierende Maßnahmen bedingt, wurden doch insgesamt ca. drei Millionen Männer für den Militärdienst mobilisiert. ${ }^{151}$ Die Mobilisierung legte jedoch ebenfalls Probleme offen, die von der deutschen Militärmission erkannt und kritisiert worden waren. So gab es keine einheitlichen Standards für die Abläufe, die je nach Provinz variierten, wobei die Mobilisierungsprobleme auch dadurch bedingt waren, dass der Krieg schlichtweg länger dauerte, als ursprünglich angenommen, so dass

1461934 erhielt Kemal von der türkischen Nationalversammlung per Gesetz den Namen Atatürk (Vater der Türken), der seine besondere Stellung innerhalb des türkischen Nationalbewusstseins bis heute widerspiegelt.

147 McMeekin, World War I, S. 38.

148 Macleod, Gallipoli, S. 155.

149 Beşikçi, Military Labor, S. 555.

150 Ozdemir, The Ottoman Army, S. 28-31 und S. 48.

151 Turkish Military Archives, Ankara, BDH, Folder 62/File 309 A/Index 005, zitiert nach Beşikçi, Military Labor, S. 558. 
es schließlich zu Widerständen gegen die Rekrutierung kam und viele Männer desertierten, um dem Schicksal so vieler bereits Gefallener zu entgehen. ${ }^{152}$

Die militärische Erfahrung, die im Unabhängigkeitskrieg ihre Fortsetzung fand, war gewiss ein wichtiger Bestandteil der gemeinsamen Erinnerung und damit ein fundamentales Element der türkischen Nation, die im Kampf gegen den Imperialismus der Großmächte geboren worden war. Atatürks Führung im Krieg gegen die ausländischen Besatzer stellte damit in direkter Linie eine Fortsetzung von Gallipoli dar, wo sich die Verteidiger, so die spätere Inszenierung, des türkischen Bodens erstmals gegen die imperialistischen Großmächte zur Wehr gesetzt hatten. ${ }^{153}$ Die nationalistische Historiographie der Türkei, wie sie von Atatürk selbst in den 1930er Jahren noch initiiert worden war, betonte dabei die Unausweichlichkeit des „Erwachens“ der türkischen Nation, die im Zuge des Ersten Weltkrieges und des Unabhängigkeitskrieges erstmals zur Geltung kam und sich erfolgreich zur Wehr setzen konnte. ${ }^{154}$ Atatürk versuchte demnach, eine Erinnerungskultur zu schaffen, die der eigenen Wahrnehmung und den Notwendigkeiten des noch jungen türkischen Nationalstaates entsprach. ${ }^{155}$

Die Verwandlung von Mustafa Kemal zu Kemal Atatürk begann mit Gallipoli, denn im Zuge der dortigen Ereignisse trat er erstmals in der Rolle eines Verteidigers osmanischer bzw. später türkischer Interessen in Erscheinung. ${ }^{156}$ Unabhängig seiner Bedeutung für die Errichtung und Festigung des modernen türkischen Staates, blieb Atatürk eine historische Figur, um die seit seinem Tod 1938 gerungen wird, da sein Andenken stets politisch aufgeladen blieb. ${ }^{157}$

Für viele, vor allem anatolische Soldaten war er die charismatische Führungspersönlichkeit, die eine Zukunft versprach, in der deren eigene Rolle die Wertschätzung erfahren würde, die sie verdienten. Der amerikanische Autor Harold C. Armstrong beschrieb diesen Umstand in seiner seit 1932 immer wieder aufgelegten Studie über den „Diktator“ Atatürk wie folgt: „Er galvanisierte den einfachen türkischen Soldaten mit neuer Courage. Sie waren bereit, ihm in die Hölle zu folgen." ${ }^{158}$ Seine Rolle bei der Verteidigung Gallipolis wurde jedoch vor dem Ende des Krieges nicht wirklich gewürdigt und als das 27. und 57. Regiment der osmanischen Armee nach dem Sieg über das alliierte Expeditionskorps offiziell ausgezeichnet wurden, wurde der Offizier Mustafa Kemal nicht explizit er-

152 Beşikçi, Military Labor, S. 558.

153 Macleod, Gallipoli, S. 155.

154 Özkirimli, Nature, S. 90.

155 Üngör, Making, S. 218.

156 Ulrichsen, First World War, S. 75.

157 Sohail, Prophets, S. 133.

158 Armstrong, Grey Wolf, S. 80. 


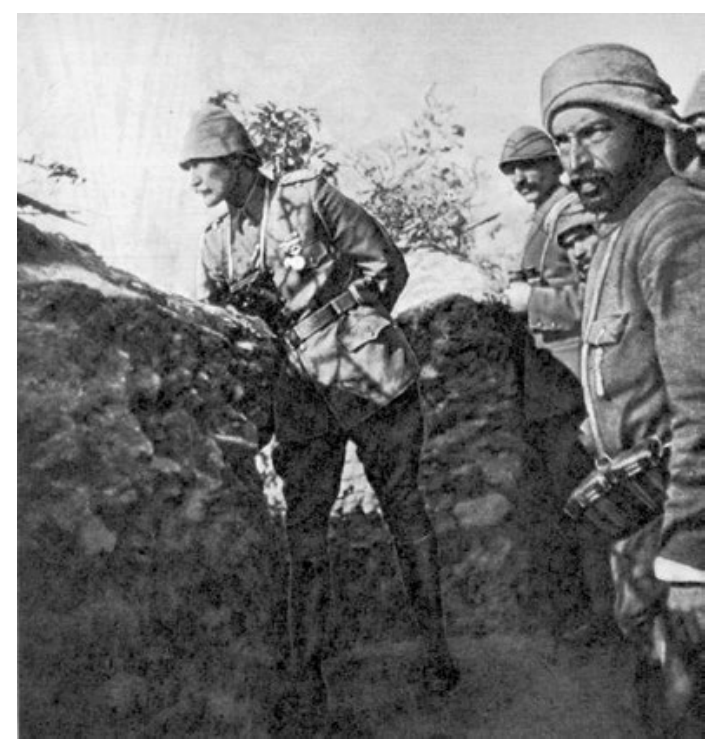

Abb. 6: Mustafa Kemal im Schützengraben während der Schlacht von Gallipoli, 1915.

wähnt, ebensowenig wie in einer offiziellen Darstellung der Ereignisse im Kriegsmagazin (Harb Mecmuası) im April 1916. ${ }^{159}$ Das heißt nicht, dass nicht auch die osmanische Regierung ein Interesse daran gehabt hätte, den Erfolg in der Schlacht von Gallipoli politisch und propagandistisch auszuschlachten, weshalb bereits im Juli 1915 prominente Intellektuelle, Dichter, Journalisten und andere Musiker oder Künstler - u.a. Ahmet Ağaoğlu (1869-1939), Ali Canib Yöntem (1887-1967), Enis Behiç Koryürek (1891-1949) und Hamdullah Suphi Tanriöver (1885-1966) - auf die Halbinsel gebracht wurden, um sich dort ein möglichst positives Bild der Lage zu verschaffen, welches sie dann als Replikatoren in der Gesellschaft des Reiches verbreiten bzw. vervielfältigen sollten. ${ }^{160}$ Dabei spielte Atatürk jedoch noch keine bedeutende Rolle. Diese wurde erst betont, nachdem er selbst an die Spitze des Staates gerückt war, so dass hier von einer Art vaticinium ex eventu, also einer post-faktisch eingefügten Weissagung eigener Größe und damit verbunden einer nachträglichen historischen Aufladung seiner eigenen Biographie gesprochen werden könnte.

Die Schlacht von Gallipoli war folglich einer der wenigen osmanischen Siege des Krieges, der gerade deshalb nationalistische Aufladung erfuhr, die aufgrund 
der weiteren Ereignisse und mit Blick auf die Biographie Atatürks zu einer Art „Initialerlebnis“ stilisiert wurde. Hier hatte sich erstmals das, was später die türkische Nation werden sollte, gegen die Ausbeutung durch westliche Großmächte erhoben. Die spätere Homogenisierung der Armee als eine türkischanatolische, wie sie sich vor allem im Zuge des Unabhängigkeitskrieges formieren sollte, war dabei ebenso post- und kontra-faktisch wie die militärhistorische Überhöhung Atatürks und seiner Rolle für den Sieg der osmanischen Armee.

Atatürks Lebensweg, der so emblematisch für den vieler anderer Jungtürken war, ${ }^{161}$ wurde allerdings zwangsläufig mit diesem wichtigen Ereignis, also dem ersten erfolgreichen Aufbäumen zum Schutz der territorialen Integrität seines Heimatlandes, das bis 1923 unter anderem aufgrund des Wirkens dieses jungen Offiziers in einen unabhängigen türkischen Staat verwandelt werden sollte, verbunden. ${ }^{162}$ Bis zum Ende des Ersten Weltkrieges war Atatürks Karriere zuvorderst eine militärische, aber als Offizier war er wie viele andere Jungtürken auch in politische Aktivitäten verstrickt. Er forderte seit 1905 eine Restauration der osmanischen Verfassung von 1876 und wurde 1908 Mitglied im jungtürkischen Komitee für Einheit und Fortschritt (KEP), welches bereits 1889 gegründet worden war. ${ }^{163}$ Nach einer Beteiligung an der Revolution der Jungtürken im selben Jahr, die im Sinne der westlichen Aufklärung nach umfangreichen und säkularisierenden Reformen strebten und sich gegen die reaktionäre Politik des Sultans Abdülhamid II. (1842-1918) wandten, ${ }^{164}$ organisierte Atatürk 1911 einen GuerillaKrieg gegen die italienische Armee in Tripolitanien, bevor er 1912/13 in den Balkankriegen eingesetzt wurde. Obwohl er dem inneren Kreis des KEP angehörte, intrigierte er gegen andere Jungtürken und die deutsche Militärmission, da er nicht akzeptieren wollte, dass einer ausländischen Macht zu viel Einfluss auf das eigene Heer gewährt werden sollte.

Im Juli 1914 befand sich Atatürk in Sofia, wo er, befördert zum Oberstleutnant, als Militärattaché für Bulgarien, Montenegro und Serbien fungierte. ${ }^{165}$ Er versuchte zunächst, auszuloten, inwieweit die bulgarische Führung bereit war, an der Seite der Mittelmächte in den Krieg einzutreten, bevor er Enver Pascha im November darum bat, in den aktiven Dienst eintreten zu dürfen. Seine Kritik an dem Militärbündnis mit Deutschland und seine Konflikte mit anderen Mitgliedern des KEP verhinderten eine solche Versetzung zunächst, allerdings wurde 1915 seinem Wunsch stattgegeben. Am 20. Januar verließ er Sofia und sollte das

161 Zürcher, Name, S. 130.

162 Mango, Sultan, S. 3.

163 Vgl. dazu Ahmad (Young Turks).

164 Dincsahin, State, S. 9; Reynolds, Empires, S. 83.

165 Seine Berichte aus Sofia wurden von Ahmet Tetik (Sofya) ediert und 2007 publiziert. 
Kommando von Einheiten zur Verteidigung der Gallipoli-Halbinsel übernehmen, die bis dato nur auf dem Papier existiert hatten und erst zusammengestellt sowie effektiv in Stellung gebracht werden mussten. ${ }^{166}$ Nachdem Atatürk sein neues Regiment im Februar 1915 in Thrakien formiert hatte, wurde er schließlich, trotz seiner langen diplomatischen Tätigkeit, an einen der Brennpunkte des Krieges geschickt. Dabei schien die Lage der osmanischen Armee alles andere als aussichtsreich, bedenkt man, dass die Operationen der Kaukasusfront bereits die Schwächen des Heeres und der osmanischen Logistik und Vorbereitung offenbart hatten.

Dessen ungeachtet waren die Verteidiger Gallipolis dazu in der Lage, die britischen Ambitionen zu durchkreuzen und die Halbinsel zu halten. Ein Ausscheiden des Osmanischen Reiches aus dem Krieg war damit verhindert, die endgültige Niederlage aber lediglich verschoben worden. Was nach dem Ende des Ersten Weltkrieges passierte, war hingegen viel wichtiger für die türkische Nationalbewegung und die damit verbundene Karriere Atatürks. Nach dem Waffenstillstand Ende 1918 wurde das osmanische Territorium von den Alliierten besetzt und das Reich verlor seine Souveränität. In dieser Situation begann Atatürk damit, eine Koalition aus Kräften einer „nationalen Befreiung“ um sich zu sammeln, um die Unabhängigkeit eines türkischen Nationalstaates zu sichern. ${ }^{167}$ Dabei konnte er von der bereits während des Krieges stattgefundenen Zentralisierung des Staates profitieren und die stärkere Einbeziehung Anatoliens in die Mobilisierung nutzen, zumal der türkische Nationalismus gerade auf dem menschlichen Potential dieser Region basieren sollte. ${ }^{168}$

Am 19. Mai 1919 landete Mustafa Kemal an der Schwarzmeerküste bei Samsun, wo er, so seine Mission, die Neunte Armee zu führen und zusammen mit den britischen Truppen gegen Banditen vorzugehen hatte. Stattdessen begann er damit, den Widerstand gegen die Besatzung zu organisieren und kontaktierte dahingehend andere nationalistische Kommandeure der Armee, wie etwa Kâzım Karabekir (1882-1948) in Erzurum und Ali Fuat Cebesoy (1882-1968) in Ankara, die ihn bei der Rückeroberung des Territoriums des ehemaligen Reiches unterstützen sollten. Es folgten mehrere Kongresse der Kemal-Unterstützer zwischen Juni und September 1919, auf denen die Prinzipien des nationalen Widerstandes formuliert wurden. ${ }^{169}$ Am 28. Januar 1920 wurde schließlich der Nationalpakt (Misak-1 Millî), das nationalistische Manifest der türkischen Unabhängigkeitsbewegung, in Ankara unterzeichnet und die Kemalisten präsentierten eine alter-

166 Hanioğlu, Ataturk, S. 72-74.

167 Kezer, Turkey, $4 \mathrm{f}$.

168 Besikçi, Mobilization, S. 1f., S. 312 u. S. 314.

169 McMeekin, World War I, S. 41. 
native Regierung, die sich der des neuen Sultans Mehmed VI. (1861-1926) widersetzte und ein Ende der Besatzung forderte. Eine Großtürkische Nationalversammlung (Türkiye Büyük Millet Meclisi), die sich ebenfalls in Ankara gebildet hatte, wählte Atatürk am 23. April 1920 zum Präsidenten. Die Spaltung war damit offiziell vollzogen und ein Krieg zwischen den türkischen Nationalisten und den Alliierten, die die Regierung Mehmeds VI. unterstützten, unausweichlich. Die alliierte Reaktion folgte schließlich im Diktatfrieden von Sèvres im Mai 1920, der das von den Nationalisten geforderte Gebiet des ehemaligen Reiches in verschiedene Interessenzonen unter französischer, griechischer und italienischer Verwaltung sowie ein unabhängiges Armenien und autonomes Kurdistan einteilte. Dieser Friedensvertrag war das Beste, was der nationalistischen Bewegung um Kemal hätte passieren können, denn es folgte ein Aufschrei und der nationale Widerstand erfuhr in der Folge des Bekanntwerdens der einzelnen Regelungen breiten Zulauf. ${ }^{170}$

Dabei war das Ziel, ein vereintes türkisches Staatsgebiet zu schaffen, zunächst beinahe unmöglich. Während sich Kemal mit der Regierung Sowjetrusslands im Vertrag von Kars am 13. Oktober 1921 über einen Interessenausgleich einigen konnte - Sowjetrussland erhielt den Kaukasus, Kemal im Gegenzug Kars und Ardahan im Nordosten der Türkei - kam es mit Griechenland im Westen zu umfangreichen Kriegshandlungen, die in der Schlacht am Sakarya (23. August 13. September 1921) ihren Höhepunkt fanden. Auf einen anatolischen Rumpf mit Ankara als Hauptstadt begrenzt, musste Kemal in diesem Augenblick siegen, wenn ein türkischer Nationalstaat überhaupt eine Zukunft haben sollte. Trotzt numerischer Unterlegenheit und unzureichender Ausstattung, gelang es den türkischen Offizieren und ihren Soldaten schließlich, den Sieg gegen das griechische Heer zu erringen und damit einen der historisch wichtigen Zäsuren für die türkische Geschichte und deren Erinnerung zu markieren. ${ }^{171}$ Die Türkei hatte ihre Unabhängigkeit also dem eigenen militärischen Erfolg zu verdanken, was die Tradierungslinien des türkischen Nationalismus der folgenden Jahrzehnte, mit seiner vor allem auch anti-griechischen Stoßrichtung, bestimmen würde. Im Vertrag von Lausanne wurde 1923 ein unabhängiger türkischer Nationalstaat anerkannt und Atatürk wurde im Oktober desselben Jahres dessen erster Präsident. $^{172}$

Nach dem Sieg der Nationalisten und der Säkularisierung des neuen türkischen Staates kam es jedoch zu Spannungen zwischen Kemal und seinen frü-

170 Ebd.

171 McMeekin, World War I, S. 42.

172 Zürcher, Name, S. 131. 
heren Unterstützern, die sich seit November 1924 in einer Oppositionspartei sammelten. Atatürk nutzte in dieser Situation eine kurdische Rebellion im Südosten des Landes, um eine Notstandsgesetzgebung zu legitimieren, die es ihm erlaubte, auch seine politischen Gegner auszuschalten und diese zu unterdrücken. Seine früheren Weggefährten - u. a. Karabekir, Rauf Orbay (1881-1964), Ali Fuad Cebesoy and Refet Bele (1881-1963) - wurden 1926 in einem Prozess angeklagt, da ihnen vorgeworfen worden war, sie hätten ein Attentat auf den Präsidenten geplant. Viele wurden zwar freigesprochen, waren aber nach der Anklage politisch isoliert, so dass Atatürk die Ereignisse vor allem dazu nutzen konnte, seine unangefochtene Position an der Spitze des neuen Staates weiter auszubauen. ${ }^{173}$ Kemals „transformative Führung“174 machte schließlich aus einem untergehenden Reich einen modernen, westlich-orientierten und säkular ausgerichteten Nationalstaat, in dem die Politik danach strebte, den Islam als identitätsstiftendes Element durch einen türkischen Nationalismus zu ersetzen. ${ }^{175}$ Das bedeutete, so der bekannte türkisch-amerikanische Historiker M. Şükrü Hanioğlu, eine „radikale Reinterpretation des Islams aus einer türkisch-nationalistischen Perspektive“176, die die Geschicke des Landes auf Jahrzehnte hin bestimmen würde.

Dass Kemal nicht gewillt war, die historischen Grundlagen seiner Herrschaft fremden Narrativen zu überlassen, zeigte er in einer Rede, die mehr als 36 Stunden dauerte und die er, verteilt auf sechs Tage während des ersten Kongresses seiner Republikanischen Volkspartei (Cumhuriyet Halk Partisi) im Oktober 1927 hielt. Darin reinterpretierte er die Ereignisse der vergangenen Jahre derart, dass nur er selbst als entscheidende und zentrale Figur innerhalb des Prozesses der Nationalstaatsgründung als Folge des Unabhängigkeitskrieges übrig blieb und somit zum unangefochtenen Helden der Ereignisse avancierte. ${ }^{177}$ Was folgte war die Etablierung eines Personenkultes um den früheren Offizier, dessen Statuen bald die zentralen Plätze des gesamten Landes vereinnahmen sollten. Dabei wurde Atatürk stets in vier verschiedenen Rollen dargestellt, nämlich als militärischer Held, der schon bei Gallipoli seinen Führungsanspruch und seine Fähigkeit, andere zu Höchstleistungen zu motivieren, unter Beweis gestellt hatte, ${ }^{178}$ als Lehrer, der die Prinzipien des neuen Staates repräsentierte und immer wieder mit verschiedenen „Weisheiten“ zitiert wurde, als Vater der Türken, der die tür-

173 Ebd., S. 132.

174 Vogel, Rebuilders, S. 513.

175 Hanioğlu, Atatur, S. 160 f.

176 Ebd., S. 132.

177 Zürcher, Name, S. 132.

178 Macleod, Gallipoli, S.159. 
kische Nation zu ihrer Größe geführt hatte, sowie als Emblem der Moderne, verkörperte er doch eine Politik der Säkularisierung und der westlich-orientierten Modernisierung der Türkei. ${ }^{179}$ Atatürks eigene Ausführungen zu den Operationen bei Gallipoli wurden erst später publiziert und die Erinnerung an Gallipoli spielte zunächst eine untergeordnete Rolle bei der Schaffung des Personenkultes, wobei das Interesse am ersten Weltkrieg generell von dem am Unabhängigkeitskrieg überschattet wurde, so dass bis 1955 gerade einmal etwas mehr als 100 Studien zu diesem Thema erschienen waren. Wenn Gallipoli erinnert wurde, dann vor allem für die Rolle Kemals, der als Atatürk später die Geschicke der Türkei bestimmen sollte. ${ }^{180}$ Verantwortlich für die Mythologisierung von Gallipoli waren deshalb eher die britischen Darstellungen. Churchill beschrieb Kemal als „Mann des Schicksals“, eine Phrase die in den weiteren Werken weitergetragen wurde und schließlich die Verbindung zwischen Atatürk und Gallipoli verfestigte. ${ }^{181}$ Das Interesse an den Ereignissen wurde zudem durch Besucher der Halbinsel wachgehalten, die bereits Mitte der 1920er Jahre dort eintrafen, um an die Orte der Schlacht zu pilgern.

Die Vermengung nationaler Politik und internationalen Interesses sorgte also dafür, dass die Ereignisse von 1915/16 mannigfach reinterpretiert wurden. Atatürk selbst betonte, dass das Schreiben von Geschichte genauso wichtig sei, wie diese $\mathrm{zu}$ bestimmen und hielt deshalb - wenig überraschend - Zeit seines Lebens ein Auge auf die nationale Geschichtsschreibung der Türkei und definierte, wie Gallipoli, der Erste Weltkrieg sowie der Unabhängigkeitskrieg zu lesen und zu interpretieren seien. ${ }^{182}$

Mag sein Wirken auch teilweise kontrovers diskutiert worden sein, Mustafa Kemal betrieb als Präsident der Türkei eine weitreichende Säkularisierung und Modernisierung nach westlichem Vorbild, wie sie beispielsweise von Japan, das als Vorbild vieler Jungtürken galt, betrieben worden war. In der Zwischenkriegszeit strebte Mustafa Kemal beispielsweise die Versöhnung mit den ehemaligen Feinden des Osmanischen Reiches an. So wurde ihm 1934 eine Antwort an die ersten offiziellen Besucher aus Australien zugeschrieben, die bis 2017 auf einem Denkmal auf der Halbinsel an der Anzac-Bucht (Anzac Cove) festgehalten war:

Die Helden die ihr Blut und ihr Leben verloren haben: Ihr liegt nun in der Erde eines befreundeten Landes, also ruhet in Frieden. Es gibt für uns keinen Unterschied zwischen den Johnnies und den Mehmets, dort wo sie Seite an Seite liegen, hier in diesem Euren Land. Ihr,

179 Zürcher, Name, S. 136.

180 Macleod, Gallipoli, S.160f.

181 Ebd., S. 162.

182 Kezer, Turkey, S. 1. 
die Mütter, die ihr Eure Söhne in entlegene Länder entsandt habt, wischt Eure Tränen weg; Eure Söhne liegen nun in unserer Brust und haben Frieden. Nachdem sie ihr Leben in diesem Land verloren haben, wurden sie auch zu unseren Söhnen. ${ }^{183}$

Damit hatte Atatürk einen versöhnlichen Kurs eingeschlagen, der die bis heute die guten Beziehungen zwischen den der Ereignisse Gedenkenden in der Türkei und Australien erklären mag.

Die Offenheit und der versöhnliche Kurs Atatürks in den Zwischenkriegsjahren mag ebenfalls mit dessen Versuch zusammenhängen, die Säkularisierung und weitere Verwestlichung der Türkei voranzutreiben. ${ }^{184}$ Dabei gelang es ihm im Gegensatz zu vielen anderen diktatorisch herrschenden und charismatischen Führern, einen Kult um seine eigene Person zu schaffen, der sich bis heute erhalten hat. ${ }^{185}$ Schon die Diskussion um die Architektur seines Mausoleums zeigte, dass es bei Atatürk selten um die Person an sich ging, sondern bei Diskussionen um den ersten türkischen Präsidenten zugleich auch immer die Frage nach der Repräsentation der Nation im Raum stand. ${ }^{186}$ Die kemalistischen Eliten, die dem Vorbild Atatürks zu folgen gedachten, stellten sich die Türkei als eine „militant säkulare, ethnisch homogene Republik, die bereit war, Teil der westlichen Welt zu werden“ ${ }^{187}$ vor und waren vollends dazu gewillt, den Islam aus dem öffentlichen Leben zu verdammen.

Atatürks Vermächtnis bestimmte deshalb die politischen Konflikte der Jahrzehnte nach dem Zweiten Weltkrieg. ${ }^{188}$ Der amerikanische Historiker Walter F. Weiker konnte 1982 somit zu Recht erklären, dass Atatürks Person noch immer das zentralste Symbol der türkischen Nation ist. ${ }^{189}$ Seit den 1990er Jahren wurde die Schlacht von Gallipoli in der Türkei wieder stärker in den Fokus der Erinnerung gerückt, ${ }^{190}$ wobei die Verbreitung des Personenkultes um Atatürk sich ebenfalls noch einmal intensivierte. ${ }^{191}$ Dabei ergibt sich ein gleichfalls ambivalentes Bild. Zum einen wird die öffentliche Rolle des Islam seit den 1990er Jahren wieder betont, ${ }^{192}$ gleichzeitig hielt sich aber der Personenkult um Atatürk sehr stark und sein Antlitz konnte einem quasi überall begegnen, ebenso wie die oben bereits

183 Fewster et al., Gallipoli, S. 2.

184 Navaro-Yashin (Faces, S. 189).

185 Weiker, Atatürk, S. 1.

186 Wilson, Identity, S. 225.

187 Çandar, Legacy, S. 89.

188 Macleod, Gallipoli, S. 168-175; Yavuz, Identity, S. 60 - 62.

189 Weiker, Atatürk, S. 1.

190 Macleod, Gallipoli, S. 175-187.

191 Özyürek, Atatürk, S. 374.

192 Yavuz, Identity, S. 79. 
genannten und ihm zugeschriebenen Verkündungen, etwa: „Die Zukunft ist im Himmel“, „Ein Land ohne Bäume kann kein Vaterland sein“ oder „Der einzige Leitfaden im Leben ist die Wissenschaft."193 Eine Möglichkeit der Interpretation des sogenannten Kemalismus und seines Einflusses auf die Türkei geht so weit, diesen mit der Aufklärung gleichzusetzen, einer Art „leitenden Philosophie die die Türken aus einer dunklen Zeit auf die Straße zur Moderne gebracht“194 hätte. Dabei lagen die Interpretationen dessen, was Moderne eigentlich bedeutet, und das nicht nur im osmanisch-türkischen Kontext, in dem diese Vorstellungen unter anderem als kolonialer Import westlicher Imperialismen $\mathrm{zu}$ begreifen sind, durchaus weit auseinander und konnten auf unterschiedlichen Faktoren basieren. ${ }^{195}$

Die Inszenierung von Atatürks Personenkult diente deshalb zugleich einer nationalen Homogenisierung, die Minderheiten wie Armenier und Kurden sowie die Geschichten der Gewalt, besonders der genozidalen Politik gegenüber den Armeniern während des Völkermordes im Zuge des Ersten Weltkrieges, ignorierte und den Menschen in der Türkei stattdessen eine personale Identifikationsfigur bot, deren Betonung nationalen Stolz, mitunter auf die Siege der osmanischtürkischen Armee bei Gallipoli sowie im Unabhängigkeitskrieg ermöglichte. ${ }^{196}$ Türkischer Nationalismus, pro-westlicher Säkularismus und die Fokussierung auf die Erfolge der Vergangenheit kulminierten schließlich in der Person Atatürks, der durch seine imaginierte Allmacht und Omnipräsenz den Weg für die Geschicke der Türkei zu weisen schien. ${ }^{197}$

Atatürks politischer Kurs steht damit diametral zu dem des heutigen Präsidenten der Türkei, Recep Tayyip Erdoğan, der zwar nicht weniger Machtpolitik betreibt als der berühmte Staatsgründer, dem aber der Wille zur Verständigung, ganz im Gegensatz zum „Vater der Türken“, abhanden gekommen zu sein scheint. Im Zuge der Einhundertjahhrfeier wurde zwar der Schlacht von Gallipoli gedacht, allerdings eher um andere historische Ereignisse, wie etwa den Genozid an den Armeniern in den Hintergrund rücken zu können. Der türkische Außenminister und spätere Ministerpräsident Ahmet Davutoğlu hatte mit Blick auf das Jubiläum im April 2011 erklärt: „Wir werden das Jahr 2015 der ganzen Welt vorstellen. Wir werden es allerdings nicht als Jahrestag eines Genozids, wie das einige Menschen behauptet haben ..., sondern als Jahrestag des glorreichen Widerstandes einer

193 Zürcher, Name, S. 129. Dazu ausführlich Özyürek (Nostalgia) und Ökten (Death).

194 Ciddi, Kemalism, S. 6.

195 Somay, Psychopolitics, S. 9.

196 Çinar, Modernity, S. 99.

197 Ebd., S. 100. 
Nation [erinnern]." ${ }^{198}$ Gallipoli war demnach zum Teil einer pragmatischen Erinnerungsverschiebung im Sinne Erdoğans geworden. Allerdings musste auch das Bild Atatürks verändert werden und so kam es 2017 im Zuge von Restaurierungsarbeiten durch die türkische Regierung dazu, dass das Denkmal mit Kemals berühmten Worten, verändert wurde. Die Kemal-Legende und ihre Repräsentation einer säkularen Türkei, die die Gefallenen der vormaligen Gegner als gleichwertige Freund betrachtete, schien sich nicht länger mit den politischen Wünschen des türkischen Präsidenten Erdoğan zu decken. ${ }^{199}$

Ungeachtet solcher Maßnahmen ist die Kemal-Legende und die Geschichte der Gallipoli-Kampagne auch heute noch von einiger Bedeutung innerhalb der türkischen Erinnerungskultur. Nachdem Gallipoli gerade in den 1980er und 1990er Jahren als wichtiger Meilenstein für die Karriere des türkischen Präsidenten betont wurde, gilt er bis zum heutigen Tag als derjenige, ohne den die Geschichte des osmanischen Sieges bei Gallipoli nicht hätte geschrieben werden können, wobei das Leben und Wirken des „bekanntesten Sohnes der Nation“200 von allerlei Legenden, besonders im Hinblick auf Gallipoli, umrankt wird. Die Erinnerung Gallipolis war jedoch nicht ausschließlich mit Atatürks Biographie verknüpft und wurde schon während des Ersten Weltkrieges für Propagandazwecke genutzt.

Im Zuge der Einhundertjahrfeiern in der Türkei zur Erinnerung an die Schlacht von Gallipoli wurden etliche türkischsprachige Darstellungen zu verschiedenen Aspekten der Kampagne veröffentlicht. Diese setzten dabei einen Trend fort, wie er sich in den letzten drei Jahrzehnten abzeichnete und in denen Gallipoli eine wesentlich prominentere Position innerhalb der türkischen Geschichtsschreibung einnimmt. ${ }^{201}$ Zuvor hatten oft nur Militärhistoriker Darstellungen publiziert, die in der Regel auch nur von einer relativ kleinen Gruppe Interessierter gelesen worden waren. Die Erinnerung an Gallipoli wurde in der Türkei, im Gegensatz etwa zu Australien, auch eher lokal am 18. März begangen, so dass die Schlacht von Gallipoli nicht zu einem national erinnerten Ereignis der türkischen Geschichte des 20. Jahrhunderts werden konnte.

Dabei hatte bereits Enver Pascha versucht, den Sieg gegen das britische Expeditionskorps für sich zu nutzen, indem eine Pressekampagne die Menschen schon während des Krieges über die Ereignisse informierte, letzten Endes aber vor allem auch, um sich deren Zustimmung zur Politik der Führung zu sichern. Po-

198 Zitiert nach Macleod, Gallipoli, S. 154.

199 Daley (Turkish Islamist).

200 Fewster et al., Gallipoli, S. 8.

$201 \mathrm{Im}$ Weiteren folgt die Darstellung Uyar (Gallipoli Campaign). 
sitive Nachrichten der ausländischen Presse wurden verbreitet, negative Meldungen, u.a. die Schilderungen deutscher Offiziere, die bereits während des Ersten Weltkrieges kritische Darstellungen veröffentlicht hatten, ${ }^{202}$ wurden zensiert. Schon ein Jahr nachdem die britische Flotte an den Verteidigungsanlagen der Verteidiger gescheitert war, wurde eine Zeremonie abgehalten, um der Ereignisse zu gedenken und an öffentlichen Plätzen wurden hölzerne Monumente errichtet, damit der Sieg der osmanischen Armee über die britisch-französischen Invasoren für alle sichtbar visualisiert werden konnte. ${ }^{203}$ Die Versuche, den Sieg gegen das Britische Empire propagandistisch zu nutzen, halfen allerdings nicht dabei, die Geschicke des Krieges zu Gunsten des Osmanischen Reiches zu verändern. Am Ende blieb nur die Niederlage.

Nach Kriegsende und noch in den Wirren des Unabhängigkeitskrieges versuchte der Chef der Kommission für Kriegsgeschichte, Major Süleymaniyeli Mehmed Emin, die Geschichte der Gallipoli-Kampagne aufzuarbeiten, allerdings wurde das Unternehmen nach dem Sieg der türkischen Nationalisten um Kemal nach 1922 nicht fortgesetzt. Andere Dinge hatten Vorrang und die Geschichte der Türkei musste nach nationalistischer Fasson geschrieben werden. Dahingehend lag der Fokus klar auf den Jahren 1919 bis 1922. Dessen ungeachtet empfahl das historische Direktorat des türkischen Generalstabes 1925, dass Veteranen des Ersten Weltkrieges ihre Erfahrungen niederschrieben, damit diese zusammen mit offiziellen Dokumenten genutzt würden, um eine offizielle Darstellung der Kriegsereignisse, ähnlich denen der deutschen Reihe Schlachten des Weltkrieges, zu präsentieren. Dabei wurden die Operationen der Schlacht von Gallipoli von mehreren Autoren, etwa Ahmed Sedad und Bursalı Mehmed Nihad, bearbeitet und in einer Mischung aus Ereignisgeschichte und persönlichen Erinnerungen veröffentlicht.

Mitte der 1930er-Jahre erhielt der junge Offizier Kadri Perk den Auftrag, eine ausführliche und offizielle Militärgeschichte der Schlacht vorzubereiten, die 1940 schließlich in drei Bänden publiziert wurde. ${ }^{204}$ Gerade Band 2 und 3 dieser Arbeit waren so geschrieben, dass sie nicht nur das Interesse von Militärhistorikern weckten, sondern durchaus breit rezipiert und gelesen wurden. Im Gegensatz

202 So etwa Erich R. Prigge (Gallipoli).

203 Besonders popular scheint die sogenannte Kanone der Tapferen (Hatıra-i Celadet Topu) gewesen zu sein, die am 12. April 1916 in Konstantinopel aufgestellt worden war. Die Kanone, von Škoda nach Vorbild einer Škoda 24-cm M 98 Haubitze gebaut, wurde zum Symbol der Tapferkeit der osmanischen Soldaten im Allgemeinen, selbst wenn sie der Gallipoli-Kampagne, wo dieser Geschütztyp in den letzten Monaten der Operationen eingesetzt worden war, gewidmet sein sollte. Uyar, Gallipoli Campaign, S. 168.

204 Vgl. Perk (Çanakkale). 
dazu erwähnte das offizielle und 1931 gestaltete türkische Geschichtsbuch für weiterführende Schulen, das vom Bildungsministerium erstellt worden war, die Gallipoli-Kampagne nur auf zwei Seiten, wobei der heroische Einsatz der türkischen Soldaten und das militärische Genie von Mustafa Kemal im Vordergrund standen. Die Heterogenität der osmanischen Armee war darin genauso verschwunden wie die Rolle der deutschen Offiziere. Gallipoli war somit zu einem türkischen Sieg geworden, der zwangsläufig auch als solcher wahrgenommen wurde.

Im Gegensatz dazu versuchten die militärischen Geschichtsschreiber, eine Hagiographie Atatürks weitestgehend zu vermeiden, blieben mit diesem Ansatz jedoch der besagt kleinen Zielgruppe ihrer Arbeiten verschrieben. Atatürk selbst zeigte in den 1930er Jahren kein Interesse an Monumentalbauten zur Erinnerung und überließ zudem anderen das Feld, wenn es um Gedenkveranstaltungen ging. Gedenkstätten für die Gefallenen waren für die führenden Politiker der noch jungen Türkei nicht von elementarer Bedeutung. Nach dem Tod Atatürks 1938 entdeckten jedoch vor allem Journalisten den Wert von Kriegserinnerungen und Geschichten, die mit den osmanischen Erfolgen, also allen voran Gallipoli, in Verbindung standen und es entstanden Artikel die Interviews, Erinnerungen und Fakten vermengten und ein durchaus breiteres Publikum erreichten. 1952 organisierte die türkische Regierung dann erstmals Besuche von Veteranen auf der Gallipoli-Halbinsel, so dass die Geschichte der Schlacht schließlich doch eine größere Öffentlichkeit erreichte und entsprechend Aufmerksamkeit erhielt. Der Bau eines ersten Monumentes wurde 1954 begonnen, das jedoch wegen Korruption und schlechter Planungen 1956 eingestellt werden sollte. Berichte darüber erregten jedoch viel Kritik und eine landesweite Spendenkampagne sicherte schlussendlich den Abschluss des Projektes: 1960 wurde dann das Denkmal der Dardanellen-Märtyrer (Çanakkale Şehitler Abidesi) eröffnet. Die Schlacht von Gallipoli hatte demnach doch noch das Interesse der türkischen Öffentlichkeit ergriffen und weitere Maßnahmen zur Erinnerung der Ereignisse sollten folgen.

Es verwundert deshalb nicht, dass die türkische Regierung seit den 1970er Jahren ein verstärktes Interesse an der Instandhaltung dieser Erinnerungskultur gezeigt hat. 1973 wurden 33.000 Hektar Land auf der südlichen Halbinsel zur Verfügung gestellt, um einen historischen Nationalpark zu stiften. Zudem wurde in den 1980er Jahren immer wieder in den Ausbau der Gedenkstätten investiert, sodass Kap Helles beispielsweise von einer über 40 Meter hohen Statue überblickt wird, die an die gefallenen Soldaten des osmanischen Heeres erinnern soll, die bei der Verteidigung der Halbinsel ihr Leben gelassen hatten. Denkmäler an beiden Seiten der Meerengen weisen zudem auf die Ereignisse hin, wobei auf der europäischen Seite unzählige weiße Steine in der Form eines Soldaten arrangiert worden waren, während eine Nachricht Reisende auffordert, doch einen Moment 
innezuhalten, um der Toten zu gedenken. ${ }^{205}$ Der Strand von Ari Burni wurde darüber hinaus 1985 offiziell auf Beschluss der türkischen Regierung in Anzac Cove umbenannt. Im Gegenzug wurde ein Park, nahe des Australian War Memorial in Canberra sowie ein Stück Land nahe der Hafeneinfahrt von Wellington mit dem Namen Atatürk bedacht. An den Gedenkfeiern des Jahres 1990, also zum 75-jährigen Jubiläum, nahmen 60 ANZAC-Veteranen - 54 Australier und sechs Neuseeländer - sowie die Regierungschefs der Staaten in der Türkei teil. Ferner kamen mehr als 10.000 Besucher, die ein weiteres Interesse an den Ereignissen hervorriefen. Im Jahr 2000 nahmen der türkische und australische Staatschef an den Feierlichkeiten teil, wodurch eine tiefe Verbundenheit im Gedenken an die Ereignisse des Ersten Weltkrieges auf der Gallipoli-Halbinsel ausgedrückt wird.

Innerhalb der Türkei wurde das gesteigerte Interesse, besonders aus Australien, durchaus bemerkt, gerade weil jedes Jahr Touristen über die Halbinsel streiften, um in den Fußstapfen ihrer Vorfahren zu wandern. Ende der 1990er Jahre wurde Moorheads Klassiker zu den Ereignissen um Gallipoli ins Türkische übersetzt, sodass dadurch die australische Perspektive einem breiten Publikum von Lesern in der Türkei zugänglich gemacht wurde. 2001 inszenierte die Staatsoper in Ankara dann das Stück Gallipoli Märtyrer (Gallipoli Martyrs), das als choreographische Inszenierung der Ereignisse einen Appell für den Frieden darstellen sollte. Ungeachtet dieser weit über die Grenzen der Türkei rezipierten Entwicklungen hat sich die türkische Tourismusindustrie, beispielsweise durch die Benennung von Hotels und Restaurants auf der Halbinsel sehr gut auf den Tourismus aus Australien und Neuseeland eingestellt. Die lokale Bevölkerung profitiert also gut einhundert Jahre nach den Ereignissen noch von Gallipoli, etwa in Form lokaler Museen, in denen Artefakte, die auf der Halbinsel zusammengetragen worden waren, gezeigt werden, oder in Form von Gästen, die durch ihre Kaufkraft die lokale Wirtschaft positiv beeinflussen. Doch auch in Australien selbst gedenken türkische Immigranten der Ereignisse von 1915/16. 1972 beteiligten sich erstmals einige solcher Immigranten an einer ANZAC-Day-Parade in Sydney, wobei derartige Beteiligungen seit den 1980er Jahren stetig zunahmen und sich die türkische Gemeinschaft positiv in die australische Erinnerungskultur integrieren konnte. Heute sind an allen Märschen in den größeren australischen Städten türkische Immigranten und deren Kinder beteiligt, die die Türkei, etwa im Jahr 2000 durch die Organisation einer osmanischen Blaskapelle, genutzt hat, um diplomatische Solidarität im Gedenken an die ANZAC-Truppen zu beweisen. Doch nicht nur in der Realpolitik des alltäglichen diplomatischen Geschäfts hielt Gal-

205 Ebd., S. 23. 
lipoli Einzug. Die türkische Literatur wurde ebenfalls von den historischen Ereignissen beeinflusst. ${ }^{206}$

Der Zerfall des Osmanischen Reiches und die Etablierung des neuen türkischen Nationalstaates machte die Konstruktion neuer nationaler Identitäten notwendig, wobei Gallipoli als Ereignis innerhalb der Geschichte des „Alten Reiches“ an Strahlkraft verlor, da sich gerade die türkische Literatur in erster Linie mit der bewegten Nachkriegsgeschichte in den ersten Jahren der Zwischenkriegszeit auseinandersetzte. Der Widerstandskampf gegen die alliierte Besatzung war von größerer Bedeutung als ein Sieg in einem Krieg, der ja doch verloren worden war. Die Wahrnehmung Gallipolis seit den 1990er Jahren änderte sich erneut, was mitunter am gesteigerten australischen Interesse, das oben ausführlich beschrieben wurde, lag. Der Erfolg gegen die britisch-französische Flotte und später die alliierten Landungstruppen hatte noch während des Krieges ein Gros an patriotischer Literatur in den letzten Zügen des Osmanischen Reiches bedingt, wobei die gewählte Textform meist eine lyrische war. Die Zeitungen und Zeitschriften des Reiches berichteten vom glorreichen Sieg an den Dardanellen und die einzelnen Zeilen besangen die heldenhaften Taten der osmanischen Soldaten. Selbstverständlich entsprachen diese den Zensurbestimmungen und wurden vom Kriegsministerium, allerdings nicht nur zur Glorifizierung, sondern auch zur Beförderung der Moral der Truppe, wohlwollend verbreitet. Was bei Gallipoli geschehen war, war die Antwort auf das Vergessen all jener, die die Macht des so lange existierenden Osmanischen Reiches und seine früheren militärischen Erfolge vergessen hatten.

Die Feinde des Reiches waren von überall her gekommen, um die Halbinsel in ihren Besitz zu nehmen und die politische Existenz der Osmanen zu beenden, doch sie waren kläglich gescheitert. Mit erhobenem Finger wurde die Politik und das Kriegsgeschick der Briten, Franzosen und Russen scharf kritisiert. Neben solchen Anklagen wurde die Rolle der Verteidiger unterstrichen, die mit ähnlichen Stereotypen bedacht wurden, wie die Soldaten im Gallipoli-Mythos der britischen Nachkriegszeit. Mutig und tapfer, ohne Rücksicht auf den eigenen Verlust hatte der osmanische Soldat erreicht, was niemand in der westlichen Welt für möglich hielt. Der Tenor der literarischen Schilderungen bis zum Ende des Osmanischen Reiches darf deshalb zu Recht als anti-westlich und nationalistisch charakterisiert werden. Das zeigte sich mitunter daran, dass der Gegner in der Regel als „Ungläubiger“, „Pirat“, „Wilder“ und „Monster“ tituliert wurde. ${ }^{207}$

206 Die weitere Analyse folgt Kirişci (Face).

207 Ebd., S. 164. 
Einer dieser Poeten, Mehmet Emin Yurdakul (1869-1944) nutzte diese Schilderungen schon früh, um einen türkischen Nationalismus zu verbreiten. Er argumentierte, dass eine ethnische Identität, die türkische, der bestimmende Faktor sei, auf dem die neue und starke Nation basieren müsse. Russland sei seiner Ansicht nach ein räuberischer Feind gewesen, der sich am Niedergang des Osmanischen Reiches eigene Gesundung versprochen und wie alle anderen, den Balkan für sich beanspruchenden Mächte, nichts weiter als ein ,blutsaugender ... Wilder“ sei. ${ }^{208}$ Der Sieg bei Gallipoli wurde schließlich in den Werken nationalistischer Färbung zu einer „spirituellen Verteidigung“ gegen „dominierende“ aber zugleich „widersprüchliche Emotionen“209 gegenüber den westlichen Großmächten: Auf der einen Seite bewunderte man die Errungenschaften des Westens, auf der anderen Seite lehnte man diesen aus Angst vor den imperialistischen Ambitionen im eigenen Land ab. Man könnte an dieser Stelle argumentieren, dass diese beiden Gefühlswelten bis heute existent sind und sich in einer pro-westlichen offenen Haltung in der Türkei, die mit einer hyper-nationalistischen, sich abschottenden und auf politische Stärke pochenden Haltung widerspiegeln. Im Gegensatz zu Atatürk, kann Erdoğan auf keine Gallipoli-Legende zurückgreifen und scheint deshalb durch eine aggressive Außenpolitik auf der Suche nach einem vergleichbaren Erfolg zu sein.

Als sich die Ereignisse 1918 zum dritten Mal jährten wurde eine Sonderausgabe der Yeni Mecmua (Neuen Rezension), die vom ehemaligen osmanischen Innenminister, Mehmed Talaat (1874-1921), der die Ereignisse im Zusammenhang mit dem Völkermord an den Armeniern einleitete, herausgegeben. Diese widmen sich ausschließlich der Ereignisse um die Schlacht von Gallipoli. Historische Schilderungen, Kurzgeschichten sowie Gedichte geben dabei die Bedeutung der Schlacht wieder, die zugleich als Ursache für die Russischen Revolutionen von 1917 angesehen wurde. So hätte die fortgesetzte Blockade der Meerengen eine Versorgung Russlands durch die Entente-Mächte Frankreich und Großbritannien unterbunden und damit aktiv zum Ausbruch der Revolution im Zarenreich beigetragen. ${ }^{210}$ Das Ende des Osmanischen Reiches selbst konnte der Sieg nicht abwenden und unabhängig von der Legendenbildung um Mustafa Kemal, verschwand Gallipoli zunächst aus dem literarischen Repertoire, dass sich eher dem türkischen Unabhängigkeitskampf der Nachkriegsjahre widmete.

Erst in den 1930er Jahren wurde versucht, das Thema erneut aufzugreifen, als Haluk Nihat Pepeyi (1898-1972) sich wieder des Stoffes annahm und 1939 einen

208 Zit. nach ebd., S. 165.

209 Ebd., S. 167.

210 Yeni Mecmua Çanakkale Özel Sayisi, S. 93-94, zit. nach Kirişci, Face, S. 168. 
Versroman vorlegte. ${ }^{211}$ Viel Aufmerksamkeit erhielt dieser nicht und es dauerte bis 1965, als der bekannte türkische Dichter Fazil Hüsnü Dağlarca (1914-2008) im Auftrag des Staates zum 50-jährigen Jubiläum der Ereignisse den Stoff aufgriff, einen Band mit mehr als einhundert Gedichten vorlegte und diesen mit der Bemerkung einleitete, dass Gallipoli das „Vorwort zur modernen Türkei“ gewesen sei. $^{212}$ Bis 1990 entstand dennoch eine erneute Lücke in der literarischen Auseinandersetzung mit dem Sujet, bevor das Jubiläenjahr erneut einen kleinen Boom bedingte. Seitdem wurde der Stoff in etlichen Romanen behandelt, wodurch die Dominanz der lyrischen Repräsentations- und Erinnerungsform abgelöst wurde. Ein Beispiel wäre etwa der Historienroman Turgut Özakmans (1930 2013), Diriliş: Çanakkale $1915^{213}$ (Auferstehung. Gallipoli 1915), der seit dem Erscheinungsjahr 2008 eine große Leserschaft fand. Selbst die Erinnerungskultur, auch im Verhältnis zu den australisch-neuseeländischen Touristen, wurde in Romanform, etwa in Buket Uzuners ( $\left.{ }^{\star} 1955\right)$ Uzun Beyaz Bulut: Gelibolu (Die lange weiße Wolke: Gallipoli, 2001) ${ }^{214}$, verarbeitet. In den meisten Darstellungen der türkischen Literatur war der Feind als Gegenbild zum osmanisch-türkischen Soldaten gezeichnet worden, um die Heldenhaftigkeit im Sinne der nationalen Größe des eigenen Staates zu unterstreichen. Dass Gallipoli im aktuellen Erinnerungsdiskurs der Türkei eher selten in Erscheinung tritt - beispielsweise in Reden zur Betonung der eigenen Größe - mag daran liegen, dass die Ereignisse zu eng mit dem Völkermord an den Armeniern zusammenliegen, weshalb eine zu breit geführte Debatte über den Ersten Weltkrieg nicht zwingend im Sinne der Regierung Erdoğan sein kann, zumindest so lange nicht, bis die „Gleichschaltung“ der Universitäten und die Abwicklung kritischer Wissenschaftler vollends abgeschlossen wurde.

\subsection{Deutschland}

In der deutschen Wahrnehmung rangierte Gallipoli ganz klar hinter anderen Schlachten des Ersten Weltkrieges, der Diskussion um den Schlieffen-Plan sowie dem Zusammenhang zwischen Erstem Weltkrieg, Deutscher Revolution 1918/19 und dem Aufstieg des Nationalsozialismus. Dass im Zuge des hundertjährigen Jubiläums der Ereignisse in deutscher Sprache nur die bereits zitierte Darstellung

211 Pepeyi (Çanakkale).

212 Dağlarca, Çanakkale Dēstam, Vorwort, zit. nach Kirişci, Face, S. 171.

213 Vgl. Özakman (Diriliş).

214 Vgl. Uzuner (Gelibolu). 
des Mannheimer Historikers Heinz A. Richter ${ }^{215}$ erschienen ist und sich zudem eher an ein Expertenpublikum richtet, belegt die Spärlichkeit der Rezeption Gallipolis im heutigen Weltkriegsdiskurs der deutschen Öffentlichkeit. Neben den mehrfach genannten Memoiren ehemaliger Gallipoli-Veteranen, wie beispielsweise Liman von Sanders, erregte die deutsche Beteiligung direkt im Anschluss an die Ereignisse des Ersten Weltkrieges nur wenig Aufsehen, sodass man zumindest im Hinblick auf die bestehende Nichtbeachtung von einer gewissen Kontinuität sprechen kann. Dabei stellen die deutsch-osmanischen Militärbeziehungen ein reichhaltiges Forschungssujet dar, das erst kürzlich in einer umfangreichen Studie über einen längeren Zeitraum betrachtet wurde. ${ }^{216}$ Die Tatsache, dass die osmanische Armee vor Beginn des Krieges unter deutscher Führung modernisiert worden war und das die Schlacht von Gallipoli, mit immerhin 3.000 beteiligten deutschen Soldaten und Offizieren, durchaus als deutsch-osmanische Militärkooperation $\mathrm{zu}$ verstehen ist, ${ }^{217}$ hatte allerdings im Zuge der Zwischenkriegszeit nur wenig Interesse von Seiten deutscher Historiker geweckt.

Neben den veröffentlichten Erinnerungen der teilnehmenden Offiziere stellte lediglich Carl Mühlmanns Darstellung zum Kampf um die Dardanellen (1927), basierend auf den Quellen des Reichsarchivs, einen Versuch dar, die Bedeutung der Gallipoli-Kampagne und die erfolgreiche deutsche Waffenhilfe für das Osmanische Reich zu belegen. Mühlmann wies explizit darauf hin, dass Gallipoli gezeigt hatte, dass das osmanische Heer durchaus dazu in der Lage war, den Angriffen von außen, sogar dem des britischen Empire, Stand zu halten, etwas, das kaum jemand für möglich gehalten hatte:

Ein Reich, [...] das im Jahre 1912 auf den ersten Anhieb seiner benachbarten Feinde zusammenzubrechen schien, verbrachte trotz seiner unvollkommenen politischen und wirtschaftlichen Organisation im Weltkriege Heldentaten, die man den glänzenden militärischen Zeiten seiner bisherigen Geschichte würdig an die Seite stellen muß.218

Mühlmann unterstrich gleichzeitig, dass dieser Erfolg ein deutscher war, denn „[z]weifellos wäre ohne deutsche Unterstützung der türkische Widerstand in

215 Vgl. Richter (Krieg).

216 Grüßhaber, Spirit, S. 26-102 stellt die deutsch-osmanischen Militärbeziehungen zwischen 1908 und 1918 hervorragend dar.

217 Ebd., S. 79. Das soll allerdings nicht darüber hinwegtäuschen, dass die osmanischen Offiziere den zunehmenden Einfluss ihrer deutschen Kollegen und die Übernahme der Kommandogewalt nicht kritiklos hinnahmen und es zu entsprechenden Auseinandersetzungen, wie etwa im Falle von Mustafa Kemal, gekommen war. Vgl. dazu ebd. S. 130.

218 Mühlmann, Kampf, S. 13. 
dieser Stärke nicht denkbar gewesen.“219 Es ging ihm also ebenfalls darum, die Leistung der 15.000 deutschen Offiziere und Soldaten ${ }^{220}$ im Dienste des Osmanischen Reiches herauszustellen.

Der ambitionierte Versuch des ehemaligen Liman-Adjutanten änderte aber kaum etwas an der allgemeinen Popularität des Sujets: Gallipoli blieb ein exotisches Thema, wenn es um die Auseinandersetzung mit dem Ersten Weltkrieg ging. Auch der Versuch Mühlmanns, die Ereignisse im Zuge des 20-jährigen Gedenkens des Weltkriegsendes 1938 noch einmal ins Gedächtnis deutscher Leser zu rufen, scheiterte weitestgehend. Der ehemalige Adjutant Liman von Sanders gab mit Blick auf die Bedeutung Gallipolis in der deutschen Erinnerungskultur zu, dass „dies Ereignis verblaßt [ist], vielleicht von manchen vergessen. Aber doch verdient die Militär-Mission im Gedächtnis des deutschen Volkes weiterzuleben. In schwerster Zeit hielt sie fern der Heimat deutsche Soldatenehre hoch und war ein stolzes Sinnbild deutscher Machtgeltung im Ausland.“221

Aufgegriffen wurde Gallipoli noch ein weiteres Mal in den 1930er Jahren, als Walter von Schoen (1889-1954), der in den 1930er Jahren einige Sachbücher für den Berliner Ullstein-Verlag verfasst hatte, sich 1937 des Themas annahm. Von Schoen, dessen Ansichten auf eine nationalsozialistische Weltanschauung schließen lassen, betonte, dass „[w]ohl kaum [...] jemals ein Winkel der Erde in der Geschichte der Völker eine so große Rolle gespielt“ hat, und „so heiß begehrt und umstritten worden [war] wie diese Meerengen““.222 Er unterstreicht die strategische Bedeutung der Meerengen, die als Lebensader zur Versorgung des russischen Verbündeten Frankreichs und Großbritanniens von unschätzbarem Wert waren und ,allein den vorzeitigen Zusammenbruch des Kolosses verhindern“223 konnten. Die besondere Bedeutung der Schlachten um die Halbinsel erschließe sich, wenn man deren Verlauf genauer betrachte, denn „nie war ein Ringen so stark an dramatischen Momenten wie hier, wo Sieg oder Niederlage auf des Messers Schneide standen, wo in strategischer und politischer Hinsicht für beide Seiten so viel auf dem Spiel stand.“224 Spezifisch im Sinne des Nationalsozialismus und scheinbar auf die Doktrinen der nationalsozialistischen Kriegsführung vorgreifend betonte der Autor die Ungleichmäßigkeit bei der Verteilung der kriegswichtigen Ressourcen: „Auf der einen Seite der Überfluß und die erdrü-

219 Ebd.

220 Ebd., S. 14.

221 Carl Mühlmann, Die deutsche Militär-Mission in der Türkei, Sonderabdruck aus: „Wissen und Wehr“, Heft 12, Berlin 1938, BArch MArch N902/7-22, S. 847.

222 Schoen, Hölle, S. 5.

223 Ebd., S. 7.

224 Ebd., S. 11. 
ckende Übermacht an modernsten Waffen und allen Hilfsmitteln. Auf der anderen der vortreffliche anatolische Soldat, der trotz unzureichender Verteidigungsmittel zäh und verbissen kämpfte, nicht wankte und nicht wich.“225 Dass letzterer den Sieg davon getragen hatte, belegt einen „Sieg des Geistes über die Materie, ein Sieg des zusammengeballten Willens über das erdrückende Material, ein[en] Sieg der psychischen Kraft über die physische.“226

Besonders hervorgehoben wird darüber hinaus fast zwangsläufig die Rolle der deutschen Offiziere und Soldaten während der Kämpfe um die Halbinsel. War schon die Anwesenheit der Schiffe der kaiserlich deutschen Marine von immenser Bedeutung, denn, so von Schoen, „noch nie haben einzelne Kriegsschiffe die Politik eines Landes so ausschlaggebend beeinflußt wie diese beiden deutschen Kreuzer“227, so war es erst den Offizieren der Deutschen Marine und Armee zu verdanken, dass sich das Osmanische Reich überhaupt verteidigen konnte, eine Perspektive, die ähnlich der britischen vor und während der Ereignisse von Kulturchauvinismus und Rassismus bestimmt war. Schließlich waren es diese von Berlin entsandten Männer, die sich mit ,glühendem Eifer, zäher Energie und großer Geduld“228 der Aufgabe widmeten, aus den unorganisierten osmanischen Einheiten eine schlagkräftige Truppe zu formen. Daher musste nach Ansicht des Autors festgehalten werden: „Wenn die türkische Armee durch diese Kämpfe eines der schönsten Ruhmesblätter ihrer Geschichte hinzufügen konnte, so haben hieran die dort streitenden Deutschen den größten Anteil.“229 Die Zahl der deutschen Mannschaften bewertend fügte er an: „Gering war ihre Zahl, aber bedeutend ihr Einfluß.“230 Die logistisch hervorragende Verteilung einer kleinen Zahl deutscher Spezialisten hätte demnach gereicht, das Osmanische Reich auf die britisch-französischen Landungen vorzubereiten und den Sieg zu gewährleisten:

Gallipoli verteidigte ein deutscher General, die Dardanellen und die Flotte waren deutschen Admirälen unterstellt, in jedem türkischen Stab, in jedem Küstenwerk, jeder Batterie waren Deutsche tätig. Ohne ihr Organisationstalent und ihre Erfindungsgabe, ohne ihre Führung und ihren vollen Einsatz in den verzweifeltsten Lagen hätte die türkische Armee nie zum Siege geführt werden, der Ansturm der feindlichen Übermacht niemals zerschellen können. ${ }^{231}$

225 Ebd., S.11f.

226 Ebd., S.12.

227 Ebd., S.9.

228 Ebd.

229 Ebd., S.12.

230 Ebd.

231 Ebd. 
In gewisser Weise drohend prophetisch wies der nationalsozialistische Jargon der Darstellung deshalb bereits zwei Jahre vor dem Beginn des Zweiten Weltkrieges darauf hin, ,was restloser Einsatz zu vollbringen vermag, wenn die Lage auch noch so hoffnungslos erscheint.“232 Am Ende blieb allerdings nichts vom Schlachtengetümmel und der von Menschenhand dirigierten Zerstörung übrig. Schon zu Zeiten Schoens war Gallipoli wieder im Nebel der Vergessenheit entschwunden:

Von goldenen Strahlen der Wintersonne übergossen, liegt in friedlicher Stille Gallipoli. Keine Geschütze donnern mehr, keine Granaten bersten, keine Kugeln pfeifen. Nur die Meereswogen rauschen an den Strand und branden gischtend an den Klippen und Felsen rings um Gallipoli. Ein leises Frühlingsahnen zieht über dieses zermarterte Land. Bald werden die Täler wieder grünen, bald wird ein Blumenflor die Stätte des Grauens überziehen, die neun Monate lang die Hölle auf Erden gewesen. ${ }^{233}$

Anders als im Falle Gallipolis, das schnell wieder in Vergessenheit geriet, interessierten sich die Nationalsozialisten für Atatürk und dessen seit dem Ende des Unabhängigkeitskrieges auch politische Herrschaft und waren damit nicht allein, denn in der Zeitschrift für Politik erschien 1937 ein Artikel zum türkischen Staatspräsidenten unter der Kategorie „Männer des Monats“. Darin wurden die Leistungen des dortigen „Führers“ würdigend zusammengefasst:

Der „kranke Mann“ ist heute gesund geworden, gesünder denn je und nimmt im politischen Kräftespiel Europas die Position ein, die ihm auf Grund seiner geopolitischen Lage durchaus zukommt. Heute werden die Geschicke des von den Schranken und Fesseln der Vergangenheit befreiten, verjüngten Volkes von dem kargen und harten Anatolien aus bestimmt, von einem Mann, der an Härte und spartanischer Anspruchslosigkeit dieser Landschaft gleichkommt - wenn nicht gar übertrifft! 234

Vergleiche mit Adolf Hitler (1889-1945), der ebenfalls eine junge politische Bewegung angeführt hatte, die im Anschluss an die Übernahme der Macht im Staat, ähnlich wie Atatürk, keine demokratische Ordnung, sondern ein Führerregime mit entsprechendem Personenkult errichtete, drängen sich dabei natürlich auf, zumal Hitler selbst entsprechende Parallelen unterstrich. ${ }^{235}$ Atatürks Türkei wurde von den Nationalsozialisten als Wegbereiter einer neuen Art völkischer Moderne begriffen, mit dem „türkischen Cäsar“ an der Spitze dieses starken und

232 Ebd.

233 Ebd., S. 242.

234 Heberlein, Atatürk, S. 168.

235 Ihrig, Atatürk, S. $109 \mathrm{f}$. 
selbstbewussten Nationalstaates, der sich gegen die Siegermächte des Ersten Weltkrieges behaupten konnte und seine eigenen Ansprüche mit Waffengewalt durchgesetzt hatte. ${ }^{236}$ Ungeachtet dieses Interesses an Atatürk und der modernen Türkei von Seiten der Nationalsozialisten blieb eine umfassende Auseinandersetzung mit der Schlacht von Gallipoli allerdings aus. In der Nachkriegszeit lag der Fokus dann zumeist auf den (zentral-)europäischen Kontexten des Ersten Weltkrieges. Seither hat sich daran kaum etwas geändert und Gallipoli wurde im deutschen Gedächtnis bisher nicht revitalisiert.

236 Ebd., S. 148. 